\title{
Impact of periodontal therapy on systemic markers of inflammation in patients with metabolic syndrome: a randomized clinical trial
}

Eduardo Montero ( $\square$ eduardomonterosolis@ucm.es )

University Complutense of Madrid https://orcid.org/0000-0003-2525-8529

Mercedes López

Universidad Complutense de Madrid

Honorato Vidal

Universidad Complutense de Madrid

María Martínez

Universidad Complutense de Madrid

Jorge Marrero

Hospital Universitario de Fuenlabrada

Leire Virto

Universidad Complutense de Madrid

David Herrera

Universidad Complutense de Madrid

Antonio Zapatero

Hospital Universitario de Fuenlabrada

Mariano Sanz

Universidad Complutense de Madrid

Original investigation

Keywords: periodontitis, metabolic syndrome, systemic inflammation, diabetes mellitus, insulin resistance

Posted Date: May 5th, 2020

DOI: https://doi.org/10.21203/rs.3.rs-25563/v1

License: (1) (i) This work is licensed under a Creative Commons Attribution 4.0 International License.

Read Full License

Version of Record: A version of this preprint was published at Diabetes, Obesity and Metabolism on August 20th, 2020. See the published version at https://doi.org/10.1111/dom.14131. 


\section{Abstract \\ Background}

Although there is evidence of positive effect of periodontal therapy on systemic inflammation, this response is highly variable among subjects. It was the aim of this clinical investigation to determine the impact of periodontal treatment on systemic markers of inflammation in patients with metabolic syndrome (MetS) and periodontitis.

\section{Methods}

In this parallel-arm, double blind, randomized controlled clinical trial, 63 patients with MetS and severe periodontitis were randomly assigned to receive intensive periodontal treatment (IPT; scaling and root planing plus azithromycin $500 \mathrm{mg}$, q.d., for three days) or minimal periodontal treatment (MPT; supragingival professional mechanical plaque removal plus a placebo). The primary outcome was the impact of the tested interventions on hs-CRP serum levels at 6 months. As secondary outcomes, differences in the levels of cytokines, markers of prothrombotic states, carbohydrate and lipids metabolism, as well as blood pressure, were measured at 3 and 6 months after therapy.

\section{Results}

The ITT population consisted on 63 subjects randomly assigned to either MPT $(n=31)$ or IPT $(n=32)$ groups. At baseline, mean hs-CRP was $3.9 \mathrm{mg} / \mathrm{L}$ (standard deviation, $\mathrm{SD}=2.9$ ) and $3.9 \mathrm{mg} / \mathrm{L}(\mathrm{SD}=3.4)$, respectively, and no significant differences in their cardiometabolic risk profiles were detected between groups. After 6 months, unadjusted mean hs-CRP were $2.9 \mathrm{mg} / \mathrm{L}$ (standard error, SE =0.4) and 4.0 (SE = $0.8)$, respectively. Adjusting for baseline hs-CRP, sex, age, smoking status and body mass index, hs-CRP was $1.2 \mathrm{mg} / \mathrm{L}$ (95\% confidence interval, [Cl 0.4; 2.0]; $\mathrm{p}=0.004$ ) lower in the IPT group than in the MPT group. In the secondary outcomes, significant reductions in IL-1 $\beta$, TNF- $\alpha, \mathrm{HbA} 1 \mathrm{c}$ and blood pressure were observed in the IPT group at 3 months, when compared to the MPT group.

\section{Conclusion}

Effective periodontal treatment significantly reduced hs-CRP after 6 months in patients with MetS and severe periodontitis. Periodontal therapy might be useful to reduce cardiovascular risk in these patients.

\section{Trial registration:}

ClinicalTrials.gov Registration Number: NCT03960216. 


\section{Background}

Metabolic syndrome (MetS) is a cluster of medical conditions associated with the risk of developing atherosclerotic cardiovascular disease (CVD) [1]. It is characterized by central obesity (defined by waist circumference), impaired glucose regulation, high blood pressure and dyslipidaemia (i.e. low high-density lipoproteins [HDL] and/or elevated triglycerides) (IDF Consensus Report, 2015). Although in certain individuals these conditions may occur in isolation, when they cluster as MetS, there is a significant increase in the risk for CVD, diabetes and overall mortality, even after adjusting for the traditional risk factors $[2,3]$. MetS is not a disease in itself, but it is a serious health condition and a major global public health concern that affects about $10-40 \%$ of adults in developed countries, in parallel with the rise in prevalence of obesity $[4,5]$. In the United States of America, its prevalence has increased from $28 \%$, in 1988-1994, to 34\%, in 1994-2004, according to the National Health and Nutrition Examination Surveys (NHANES) [6].

Periodontitis is a highly prevalent chronic inflammatory disease characterized by the destruction of tooth supporting tissues, eventually leading to tooth loss and significantly impairing the patient's quality of life. In fact, severe periodontitis is one of the most prevalent diseases worldwide, with an age standardized prevalence of $9.8 \%$ and with approximately 796 millions of cases [7]. Several epidemiological studies and systematic reviews have consistently shown an association between periodontitis and an increased risk for future atherosclerotic cardiovascular events, independently of traditional risk factors [8]. This association has been explained by the systemic effect of this infectious disease, evidenced by a significant increase in C-reactive protein [hs-CRP]) and other biomarkers of systemic inflammation, which may contribute to the overall inflammatory burden and to an increased risk of atherogenesis and hyperglycaemia [9-11].

A recent systematic review with meta-analysis has shown evidence for a potential association between periodontitis and MetS [11-14]. This association may be explained by the shared chronic state of systemic inflammation in both conditions [15], resulting in oxidative stress and insulin resistance [1618]. This bi-directional association may be explained by the increase of systemic inflammation as a consequence of periodontitis, that may act as a contributor to the development of MetS [11]; while the low-grade systemic inflammation characteristic of obesity and impaired glucose regulation may negatively affect the periodontal status [19].

The possible effect of periodontal treatment on systemic inflammation, has been reported in several studies assessing the levels of inflammatory markers after treatment, showing significant reductions in interleukin (IL)-6 and hs-CRP [20-22]. However, this systemic impact has not been consistent and the variability in the reported outcomes has been attributed to inclusion of patients without clear measures of exposure, based on clinical or radiographic surrogates, rather than on the actual infectious burden, what may not reflect the degree of chronic inflammatory exposure [23, 24]. Also, the selection of patients may have not included those with relevant risk for CVD $[25,26]$. 
It was, therefore, the purpose of this parallel-arm, double blind, randomized controlled clinical trial, to determine whether the treatment of periodontitis in patients with MetS could reduce the cardiometabolic risk, measured by means of: i) markers of systemic inflammation and prothrombotic states (hs-CRP, a-1 antitrypsin and fibrinogen levels); ii) pro-inflammatory cytokine profiles; and, iii) markers of carbohydrate and lipid metabolism.

\section{Methods}

\section{Study design and participants}

This study was designed as a parallel-group, double-blind, single-centre, randomized clinical trial (RCT), with a 6-month follow-up. Patients were recruited among those diagnosed of MetS and included in an active program of cardiovascular risk prevention at the Fuenlabrada University Hospital (Madrid Regional Hospital Network, Fuenlabrada, Madrid, Spain). The study protocol was approved by the institutional ethic committee (Internal Code 12/206, Hospital Clínico de San Carlos, Madrid) and registered at ClinicalTrials.gov (NCT03960216). This RCT was conducted between November 2012 and June 2018.

Participants were consecutively enrolled into the study if they fulfilled the following criteria:

- age 35 to 65 years,

- diagnosis of MetS according to the criteria established by Alberti et al. (2009) [27], based on the presence of, at least, three of the following risk factors:

- elevated waist circumference (WC) ( $\geq 94 \mathrm{~cm}$ in men, $\geq 80 \mathrm{~cm}$ in women),

- elevated triglycerides ( $\geq 150 \mathrm{mg} / \mathrm{dL})$,

- reduced high density lipoprotein (HDL) cholesterol ( $<40 \mathrm{mg} / \mathrm{dL}$ in males; $<50 \mathrm{mg} / \mathrm{dL}$ in females),

- elevated blood pressure (systolic $\geq 130$ and/or diastolic $\geq 85 \mathrm{~mm} \mathrm{Hg}$ ),

- elevated fasting plasma glucose (FPG) ( $\geq 100 \mathrm{mg} / \mathrm{dL})$,

- presence of, at least, 16 teeth,

- diagnosis of stages III-IV generalised periodontitis, according to the criteria of the 2018 EFP-AAP classification [28],

- presence of, at least, eight sites with probing pocket depth (PPD) $\geq 6 \mathrm{~mm}$ and four sites with clinical attachment level (CAL) $\geq 5 \mathrm{~mm}$, distributed in, at least, two different quadrants [29]; with the objective of recruiting participants with severe periodontal destruction (defined by CAL) and a high level of inflammation (defined by PPD).

Participants were excluded in presence of: 
- uncontrolled systemic diseases other than diabetes or hypertension (e.g. chronic kidney disease, chronic lung disease, acute pulmonary disease during the previous 3 months, history of stroke, myocardial infarction, angor pectoris or revascularization during the previous 6 months, neoplasms, etc.),

- history of any surgical treatment in the previous 3 months,

- alcoholism or psychiatric disorders,

- history of systemic antibiotic usage over the previous 3 months,

- non-surgical periodontal treatment during the previous 6 months, or surgical periodontal treatment over the previous 12 months.

All the patients recruited according to these criteria and willing to participate in the study received verbal and written information. Upon signing the approved consent form, they were referred for periodontal treatment to the Postgraduate Clinic of Periodontology, at the Faculty of Odontology (University Complutense of Madrid, Spain).

\section{Study interventions}

All patients received standardised oral hygiene instructions (consisting on the use of a manual toothbrush and specific inter-dental brushes) and when indicated, extraction of hopeless teeth. Then, patients were randomized to:

- an intensive periodontal treatment (IPT; test group), which consisted on two sessions (one week apart) of non-surgical subgingival instrumentation (scaling and root planing, SRP), under local anaesthesia, with a combination of ultrasonic scalers (Minipiezon Electromedical Systems EMS, Nyon, Switzerland) and hand curettes, together with adjunctive administration of a systemic antibiotic (azithromycin $500 \mathrm{mg}$, q.d., for three days), administered at the last session of SRP.

- A minimal periodontal treatment (MPT; control group), which consisted on two sessions of supragingival professional mechanical plaque removal, eliminating supragingival plaque and calculus with an ultrasonic scaler, without subgingival instrumentation, together with the adjunctive administration of placebo medication (identical capsules containing lactose $500 \mathrm{mg}$, q.d, for 3 days) administered at the last session of SRP.

Both treatment groups received, after the first treatment session, an antiseptic mouth rinse, containing $0.12 \%$ chlorhexidine and $0.05 \%$ cetylpyridinium chloride (Perio-Aid $0.12 \%$; Dentaid, Barcelona, Spain), to be used b.i.d., for 14 days. Oral hygiene instructions were reinforced in both groups at the 3-and 6-month visits, but no additional periodontal treatment was provided during the study, unless a subject demonstrated periodontitis progression, defined as presence of interproximal attachment loss $\geq 3 \mathrm{~mm}$ in $\geq 2$ teeth [30]. These patients were withdrawn from the study and immediately received the appropriate periodontal treatment. 


\section{Randomization and masking}

Patients were randomly assigned to receive IPT or MPT (1:1) using a computer-generated list, with a random-block size of 20. Allocation concealment was ensured with the use of opaque envelopes, opened at the time of the start of periodontal treatment, by the assigned clinicians (HV and EM). Patients were unaware of the assigned treatment group and the provided adjunctive medication (azithromycin or placebo) were externally identical capsules, numbered according to the randomization list. All other investigators [clinical examiners, laboratory staff, staff involved in data collection (MM)] were masked to the group allocation.

\section{Study flow}

Two trained and calibrated clinical examiners (EM and $\mathrm{ML}$ ) collected medical histories and carried out a comprehensive oral and periodontal examination, at baseline, and at each follow-up visit (3 and 6 months after therapy). Periodontal parameters included full-mouth measurements of PPD, CAL, bleeding on probing (BOP), plaque index (PII) [31] and gingival index (GI) [32], at 6 sites per tooth, excluding third molars, using a UNC-15 probe (Hu-Friedy; Chicago, Illinois, USA). Full-mouth periapical radiographs and/or a panoramic radiograph were also taken at baseline. Before the start of the study, clinical examiners were calibrated. The calibration exercise consisted on repeated measurements of five volunteer patients. The achieved inter-examiner intraclass correlation coefficient for CAL was 0.98 (95\% confidence interval -Cl: [0.97; 0.98]) and for PPD 0.98 (95\% Cl: [0.98; 0.98]). Exposure to tobacco smoking was registered as current (number or cigarettes and years of exposure were noted), former (those who had stopped smoking at least 1 year previously) or never smoker. Measurements of weight, height, waist circumference and blood pressure were carried out at baseline and at the 3-and 6-month examinations. History of any other used medication was collected at baseline and updated at each study visit.

Fasting blood samples were collected at baseline, and at each study visit, into three $7 \mathrm{~mL}$ ethylenediaminetetraacetic acid (EDTA)-containing tubes. One EDTA-containing tube was stored at the Hospital at $-80^{\circ} \mathrm{C}$, for later analysis of hs-CRP, a-1 antitrypsin, fibrinogen, white blood cell counts (WBC), glycated haemoglobin (HbA1c; using high-performance liquid chromatography), FPG, insulin, creatinine and standard lipid fractions [total cholesterol, HDL cholesterol, LDL (low-density lipoprotein) cholesterol and triglycerides]. The other two tubes were stored at $-80^{\circ} \mathrm{C}$ for later determination of cytokine profiles [IL$1 \beta$, IL-6, IL-18 and tumour necrosis factor (TNF)-a) at the Molecular Biology Laboratory (Faculty of Odontology, University Complutense of Madrid), by means of multiplex assays.

At baseline, and 3 and 6 months after treatment, microbiological samples were collected before the periodontal examination. In brief, after removing the supra-gingival biofilm with sterile cotton rolls and gently air-dried to eliminate any contamination with saliva, two consecutive sterile medium paper points (\#30, Maillefer Ballaigues, Switzerland) were inserted in the four deepest pockets showing BOP, one per quadrant, and left in place for 10 seconds. Paper points were transferred into one common vial, containing $1.5 \mathrm{~mL}$ of reduced transport fluid (RTF) [33]. Detailed information on laboratory procedures for the microbiological analyses is provided in Supplementary Materials. 


\section{Outcomes}

To assess the efficacy of the tested interventions on periodontal health, mean periodontal clinical parameters (PPD, CAL, BOP, PII, GI), and mean counts, proportions and frequency of detection of target periodontal pathogens (Aggregatibacter actinomycetemcomitans, Tannerella forsythia, Porphyromonas gingivalis, Prevotella intermedia, Parvimonas micra, Campylobacter rectus and Fusobacterium nucleatum) were compared at 3 and 6 months.

Compliance with antibiotic intake and occurrence of adverse events (any change in anatomical, physiological or metabolic functions occurring in any phase of the clinical study, whether or not associated with it, were also registered. Patients were exited from the study, in presence of serious adverse effects under the criteria of the medical principal investigator (AZ) or when the criteria for periodontitis recurrence were met.

The primary outcome was the evaluation of the differences between the test and control groups in the mean hs-CRP serum levels at 6 months after the periodontal intervention. As secondary outcomes, the mean levels at 6 months of $a-1$ antitrypsin, fibrinogen, inflammatory markers (IL-1 $\beta$, IL-6, IL-8 and TNF-a), $\mathrm{HbA1c}$ FPG, insulin, lipid fractions and blood pressure were compared.

Homeostasis Model Assessment scores (HOMA2-IR, HOMA2- $\beta$ and HOMA2-IS) were calculated with a HOMA2 calculator released by the Diabetes Trial Unit, University of Oxford: HOMA Calculator (https://www.dtu.ox.ac.uk/homacalculator/). The concentrations of IL-1 $\beta$, IL-6, IL-8 and TNF-a were measured using high-sensitivity multiplex map human immunoassays (Millipore ${ }^{\circledR}$ corporation, Cat. \#HSTCMAG-28SK, Billerica, MA, USA) using a Luminex-200 System Unit with the XY platform (Luminex® Corporation, Oosterhout, Netherlands). Detailed information on laboratory procedures for the immunoassays is provided in Supplementary Materials.

\section{Data analysis}

The sample size calculation was based on detecting a mean difference between groups of $2 \mathrm{mg} / \mathrm{L}$ in serum hs-CRP levels with an estimated standard deviation (SD) $=2.5 \mathrm{mg} / \mathrm{L}$. To detect statistically significant differences $(a=0.05)$ with an $80 \%$ power, a minimum of 25 subjects per group were needed, which including an expected $20 \%$ drop-out rate, resulted in a final sample of 30 participants per group.

Data were reported as mean and SD, unless otherwise specified [e.g. $n(\%)$ ]. All analyses were performed using the intention-to-treat population and the last observation carried forward (LOCF) approach for missing values. Analyses were repeated for all primary and secondary outcomes using post-hoc missing-value analyses. In addition, per-protocol analyses were conducted for all outcomes; the estimates derived from these analyses were reported for the primary outcome (hs-CRP) and any secondary or post-hoc outcomes, if they differed from estimates obtained in the intention-to-treat population.

The primary and secondary outcomes were modelled using multilevel linear regression. The models included the respective baseline measurement, treatment group, study visit (i.e. baseline, 3 months and 6 
months), and a treatment-time interaction term as explanatory variables (covariates). Additional covariates included the main risk determinants for CVDs and periodontitis (i.e. age and sex) and the main risk factors also linked to a worse clinical periodontal outcome after treatment [i.e. smoking status and body mass index (BMI)]. Natural logarithmic transformation of the data, where appropriate, was applied. Differences between study groups for primary and secondary outcomes at all study follow-up visits (3 and 6 months) were adjusted for the respective baseline values, whereas the absolute values for each treatment group at a given time-point were not. For all analyses, a two-sided p value of less than 0.05 was considered as significant. The analyses were carried out using STATA version 13.1 with SVY package (StataCorp College Station, TX, USA).

\section{Results}

\section{Patient characteristics}

Between November 28, 2012, and December 11, 2017, 854 subjects with MetS were screened, being 765 excluded since they did not meet the study criteria and $63(70.8 \%)$ out of 89 subjects were finally enrolled and randomly assigned to either the test-IPT $(n=32)$ or the control-MPT $(n=31)$ groups (Fig. 1$)$. Three patients $(5 \%)$ were lost in both groups over the 6-month period. These patients did not significantly differ from the included participants in regard to any of the outcome variables considered in the study. All included subjects were Caucasians. Two major adverse events occurred during the course of the study, one in a patient in the test (hospitalization for urine infection), and the other in the control group (acute myocardial infarction). These events were not considered to be related to the study, and they did not prevent the patients from attending the follow-up visits. Occurrence of minor adverse events were similar between the study groups (Table S1).

The cardiometabolic risk profiles at baseline (Table 1) did not show any significant difference between groups. Participants were predominantly men (around 70\% in both groups), aged between 50 and 65 years and mostly either never or former smokers $75.9 \%$ in the IPT group and $89.3 \%$ in the MPT group). Subjects in both groups presented a mean BMI close to class 3 obesity $\left(39.1 \mathrm{~kg} / \mathrm{m}^{2}\right.$ for the IPT group and $38.0 \mathrm{~kg} / \mathrm{m}^{2}$ in the MPT group; $p=0.618$ ) and a mean $W C \approx 120 \mathrm{~cm}$, indicative of prominent visceral fat storage. High hs-CRP levels were observed in both groups, with $53.1 \%$ and $54.8 \%$ of patients in IPT and MPT groups, respectively, presenting values $\geq 3 \mathrm{mg} / \mathrm{L}$. The percentage of subjects with HbA1c levels $\geq 7 \%$ were $31.25 \%$ and $25.8 \%$, respectively. No differences between groups were observed in the medication use at baseline (Table S2) and changes in medication throughout the study were negligible [n $=3(4.8 \%)$; corresponding to an increase in insulin dosage]. Nine patients (two in the test and seven in the control group) received systemic antimicrobials during the study (apart from the one administered in the IPT group), but differences between groups were not statistically significant $(p=0.070)$.

\section{Clinical and microbiological periodontal outcomes}


Periodontal clinical parameters were similar at baseline in both groups (Table 2. Figure 2). The mean number of teeth at baseline in the IPT and MPT groups were $22.6(S D=3.8)$ and $22.0(S D=4.2)(p=$ $0.611)$, respectively; with a similar number of tooth extractions performed in both groups $[0.7(S D=1.5)$ and $0.2(S D=0.5)$, respectively $(p=0.130)]$.

As compared with the MPT group, the IPT had lower values for PII at 6 months (absolute difference, 0.4; $95 \% \mathrm{Cl}$ : [0.1; 0.7]; $\mathrm{p}=0.003$ ). Patients in the IPT group had lower scores for BOP (absolute difference, $31.1 \% ; 95 \% \mathrm{Cl}$ : $22.3 ; 40.0] ; \mathrm{p}<0.001)$ than those in the MPT group, 6 months after therapy. Similarly, patients in the IPT group had significantly less sites with PPD $\geq 4 \mathrm{~mm}(32.6 \%$; $95 \%$ Cl: $[23 ; 42]$; $p<0.001)$ and experienced a significantly higher CAL gain, than the control group, 6 months after therapy $(1.0, S D=$ $0.8 \mathrm{~mm}$, versus $0.3, \mathrm{SD}=0.6 \mathrm{~mm}$, respectively $(\mathrm{p}<0.001)$.

The microbiological outcomes, expressed as counts and proportions of each target bacterial species, at each time point, are presented in Tables S3 and S4. At baseline, both test and control groups harboured similar proportions of periodontal pathogens (P. gingivalis in $15.6 \%$ and $20.5 \%$, respectively, and $P$. intermedia in $5.5 \%$ and $6.3 \%$, respectively). Total anaerobic counts were not significantly different between groups throughout the study, although significant reductions occurred in the IPT group, 3-and 6 months post-treatment. Similarly, the counts of $P$. gingivalis were significantly lower in the IPT group, to the MPT group, at 3- $(6.9$ In CFUs; $95 \%$ Cl: [4.0; 9.9]; $p$ < 0.001) and 6 months (6.6 In CFUs; 95\% Cl: [3.5; 9.6]; $\mathrm{p}$ < 0.001). Significantly reduced counts were also found for $P$. intermedia $(5.7 \mathrm{In} \mathrm{CFUs;} 95 \% \mathrm{Cl}$ : [2.9; 8.5]; $p<0.001$; and 3.1 In CFUs; $95 \% \mathrm{Cl}$ : [0.3; 6.0]; $p=0.031$ ) and T. forsythia (5.7 In CFUs; 95\% Cl: [3.2; 8.2]; $\mathrm{p}<0.001$ and 3.1 In CFUs; $95 \% \mathrm{Cl}$ : $0.2 ; 6.0]$; $\mathrm{p}=0.035)$, in the IPT group, at 3 - and 6 months post-therapy.

\section{Impact of the interventions in the systemic inflammatory status}

The primary outcome, mean hs-CRP concentration, was reduced after 3 and 6 months in the patients in the test group (IPT), but not in the control group (MPT) (Fig. 3). Differences between treatment groups (adjusted for age, sex, smoking status, BMI and baseline hs-CRP) was $1.4 \mathrm{mg} / \mathrm{L}(95 \% \mathrm{Cl}[0.5 ; 2.2] ; \mathrm{p}=$ $0.001)$ at 3 months and $1.2 \mathrm{mg} / \mathrm{L}(95 \% \mathrm{Cl}[0.4 ; 2.0] ; \mathrm{p}=0.004)$ at 6 months (Table 3$)$. Post-hoc analyses showed that the proportion of IPT patients with hs-CRP levels $\geq 3 \mathrm{mg} / \mathrm{L}$ decreased significantly from $53.1 \%$ at baseline to $40.6 \%$ (3 months) and to $43.8 \%$ ( 6 months) with $p$ values $<0.001$ for both time points. The proportion of MPT patients with hs-CRP levels $\geq 3 \mathrm{mg} / \mathrm{L}$ increased from $54.8 \%$ at baseline to $58.1 \%$ at 3 and 6 months $(p<0.05)$. The odds ratio for a patient to move from a hs-CRP value $\geq 3 \mathrm{mg} / \mathrm{L}$ to a hs-CRP value $<3 \mathrm{mg} / \mathrm{L}$, if assigned to the IPT group versus the MPT group, was 5.4 ( $95 \% \mathrm{Cl}$ [1.0; 31.6]; $p=0.040)$. At 6 months, the percentage of patients in the IPT group experiencing a reduction in hsCRP levels was $68.8 \%$, while this percentage was $29.0 \%$ in the MPT group $(p<0.001)$.

Among the variables included in the multilevel linear regression (treatment group, baseline hs-CRP values, age, sex, smoking habit and BMI), only belonging to the IPT group $(p=0.004)$, baseline hs-CRP levels $(p<$ $0.001)$ and being a smoker $(p=0.014)$, significantly and independently predicted the variance of hs-CRP decline over 6 months. Further analyses indicated a significant interaction between smoking status and treatment group $(p<0.001)$ with post-hoc testing demonstrating that the differences in hs-CRP reduction 
were statistically significant between groups only in never-smokers $(p=0.022)$ and former-smokers $(p=$ 0.001). However, this finding may be associated with the small number of current smokers in the MPT group $(n=3)$.

In the secondary outcomes, significant reductions in IL-1 $\beta$ and TNF- $\alpha$ at 3 months were observed in the IPT group, when compared to the MPT group (Table 3). However, differences between groups were observed for these biomarkers at 6 months, neither for the other inflammatory markers (a-1 antitrypsin, fibrinogen, white blood cell count, IL- 6 and IL-8) at any time point after therapy. No differences in BMI or waist circumference between patients in the IPT or MPT groups were observed throughout the study.

\section{Metabolic, vascular and renal outcomes}

$\mathrm{HbA1c}$ was reduced, after 3 months, in patients in the IPT group when compared to the MPT group (Table 4, Fig. 4), with a difference, after adjustment for covariates, of $0.3 \%(95 \% \mathrm{Cl}$ : $[0.1 ; 0.6] ; \mathrm{p}=0.013)$. Post-hoc analyses showed that the proportion of patients with $\mathrm{HbA} 1 \mathrm{c} \geq 7 \%$ decreased significantly in the IPT group, from $31.25 \%$ at baseline to $18.8 \%$ at 3 months $(p=0.028)$, with no changes in the MPT group. No differences between groups were observed at 6 months. FPG, fasting insulin concentrations, HOMA2 scores and lipid fractions did not significantly differ between groups or visits. The multilevel linear regression determined that the variance in $\mathrm{HbA} 1 \mathrm{c}$, observed at 3 months, was only significantly predicted by being in the IPT group $(p=0.013)$ and by the baseline HbA1 percentage $(p<0.001)$, without any significant additional effect in the model for age, sex, BMI or smoking status.

IPT significantly reduced blood pressure at 3 months (Table 4, Fig. 4). Systolic blood pressure was significantly reduced at 3 months in the IPT group, when compared to the MPT group, after adjustment for covariates $(7.3 \mathrm{~mm} \mathrm{Hg} ; 95 \% \mathrm{Cl}:[1.9 ; 12.6] ; p=0.008)$. The reduction for diastolic blood pressure in the IPT group, when compared to the MPT group, lasted for 6 months (at 3 months, $7.8 \mathrm{~mm} \mathrm{Hg} ; 95 \% \mathrm{Cl}$ : [1.3; 14.4]; $p=0.019$; at 6 months, $11.0 \mathrm{~mm} \mathrm{Hg} ; 95 \% \mathrm{Cl} 2.9,19.1 ; p=0.009)$. No differences in creatinine between patients in the IPT or MPT groups were observed throughout the study.

\section{Discussion}

The present study has demonstrated that an effective periodontal treatment in patients with severe periodontitis and MetS results in significant reductions of systemic inflammation and atherosclerotic risk biomarkers. The tested periodontal treatment, consisting on non-surgical subgingival instrumentation with adjunctive systemic antibiotic administration (azithromycin 500 mg, q.d., for three days), when compared to a control group with community periodontal care (supragingival plaque control), resulted in statistically significant reductions of hs-CRP, IL-1 $\beta$ and TNF- $a$ at 3 months, and hs-CRP at 6 months. Furthermore, significant improvements in vascular function and significant reductions in $\mathrm{HbA} 1 \mathrm{c}$ also occurred in the test group.

The impact of this tested periodontal intervention on hs-CRP was a $30.8 \%$ reduction from baseline values and a difference of $1.2 \mathrm{mg} / \mathrm{L}$ at 6 months when compared with the control treatment. These results show 
that the improvements in periodontal health in these MetS patients, in spite of being actively following strict cardiovascular risk reduction protocols (including specific cardioprotective drug therapies), significantly improved their hs-CRP levels, and hence their cardiovascular risk, since it has been recently reported that hs-CRP reductions significantly reduces cardiovascular events, cardiovascular mortality and all-cause mortality [34].

These results are coincident with a previous RCT evaluating the effect of periodontal treatment in patients with MetS, also reporting significant reductions of hs-CRP levels at 12 months, although in that trial no significant differences among the treatment groups were detected, when comparing the additional effect of adjunctive use of systemic antibiotics [35].

Since MetS is a cluster of medical conditions associated with cardiovascular risk, these results would, therefore, apply to any condition with increased cardiovascular risk. Indeed clinical trials and systematic reviews with meta-analyses, evaluating the impact of periodontal treatment in CVD patients undergoing secondary prevention, have shown similar outcomes [36-41]. Bokhari et al., assessing the impact of periodontal treatment in patients with coronary heart disease (CHD) and periodontitis, reported a $30 \%$ decrease in mean hs-CRP levels [37]. In contrast, the results from the Periodontitis and Vascular Events (PAVE) study carried out in CHD patients with periodontitis, reported that periodontal therapy was not able to maintain the reduction of serum hs-CRP levels at 6 months. However, this study population did not have severe periodontitis and the periodontal therapy rendered was not able to demonstrate a significant effect on the periodontal parameters, when compared with the control group, with community periodontal care. In the present investigation, however, all patients had severe periodontitis, and there was a clear and significant improvement in all periodontal outcomes in the test group, when compared with the control group. These facts should clearly explain the reported differences between the studies

In spite of the fact that periodontitis is defined as a chronic multifactorial inflammatory disease associated with dysbiotic plaque biofilms [28], most of the previous reports evaluating the impact of periodontal treatment on cardiovascular risk have relied on surrogate markers of exposure, either clinical (probing depths) or radiographic (bone loss), but they did not assess the exposure by measuring the bacterial burden or the presence of putative pathogens. In the present investigation we have identified high counts of anaerobic bacteria and high proportions and counts of $P$. gingivalis, a keystone periodontal pathogen strongly associated with periodontitis, in all patients at baseline. The tested intervention significantly reduced, both the counts of anaerobic bacteria and $P$. gingivalis. Although previous cross-sectional studies have shown an independent significant association between presence of a significant subgingival bacterial burden and levels of periodontal pathogens with surrogate measurements of atherosclerotic risk as intima-media thickness (IMT) or hs-CRP [42, 43], this is the first RCT demonstrating that effective periodontal treatment significantly reduced these microbiological exposure measurements and that this microbiological impact was associated with significant reductions in hs-CRP. 
The impact of periodontal therapy on inflammatory cytokines (IL-1 $\beta$, IL- 6 , IL-8 and TNF- $a$ ) was also evaluated at 3 and 6 months. IL1- $\beta$ and TNF- $\alpha$ showed significant reductions at 3 months, but not at 6 months. These results are also in agreement with a recent RCT in periodontitis patients with type 2 diabetes, where significant differences between groups were noted in TNF- $a$ after treatment [40], and corroborate the referred impact of an effective periodontal treatment on cardiovascular risk, since both IL$1 \beta$ and TNF-a have a pro-atherogenic effect and have been associated as significant and independent predictors of cardiovascular events and overall mortality [44].

Other significant improvements associated to the effective periodontal treatment were the significant reductions $(0.3 \%)$ in $\mathrm{HbA} 1 \mathrm{c}$, at 3 months, and a significant reduction in arterial blood pressure, thus suggesting that this effect was not limited to the improvement in systemic inflammation, but also on the vascular function and metabolic control. In fact, periodontal inflammation has been associated with both insulin resistance and endothelial dysfunction $[39,45,46]$. The fact that the significance in HbA1c reduction in the treatment group was lost at 6 months, may be due to the lack of repeated periodontal interventions during the course of the study. Effective periodontal maintenance care has shown in other studies to maintain the positive effect in the glycaemic control $[29,38,40]$.

Similarly, recent studies have shown a significant association between periodontitis and hypertension and have suggested that periodontal treatment could reduce arterial blood pressure $[47,48]$. In this RCT, we have reported an adjusted statistically significant reduction of systolic and diastolic blood pressure ( 7.8 and $7.3 \mathrm{mmHg}$, respectively), three months after effective periodontal treatment. These findings may be meaningful, since a $10 \mathrm{mmHg}$ reduction in systolic blood pressure or a $5 \mathrm{mmHg}$ reduction in diastolic blood pressure has been associated with a $25-30 \%$ reduction of cardiovascular events [49], and half of the hypertensive adults, remain poorly controlled in spite of effective medications [50].

The present clinical trial, however, may have relevant limitations. One is that the tested intervention consisted on a combination of subgingival debridement and the adjunctive administration of azithromycin. This antibiotic has shown significant reductions in a global inflammatory score comprised by hs-CRP, IL-1 $\beta$, IL- 6 and TNF- $a$, at 6 months, but not on CRP alone[51], and hence, the cardiovascular effect shown in this study could be attributed to the antibiotic rather than the periodontal therapy. However, the adjunctive use of systemic antimicrobials to subgingival instrumentation is clearly justified by the periodontitis severity in the selected sample, since this modality of therapy has demonstrated a significant added effect on clinical and microbiological outcomes when compared to subgingival debridement alone in severe periodontitis patients [52], as well as in randomized clinical trials evaluating the impact of intensive periodontal therapy in cardiovascular risk outcomes $[40,46]$.

Another possible limitation could be the selection of the main outcome variable (hs-CRP) as a surrogate for cardiovascular risk, since its predictive value may be limited [53], although this is the biomarker most frequently reported in screening and cardiovascular risk reclassification [54-56]. Further investigations should also focus on other surrogate measures of subclinical atherosclerosis, like the coronary artery calcium (CAC) or, when possible, on true endpoints, such as major cardiovascular events. 


\section{Conclusions}

In conclusion, the results of the present study provide evidence that effective periodontal therapy reduced the cardiovascular risk in patients with MetS and severe periodontitis by significantly reducing hs-CRP levels, pro-inflammatory mediators, blood pressure and HbA1c levels. Larger studies with longer follow-up are needed to determine whether these shown short-term benefits can be sustained long-term and result in reductions in the cardiovascular morbidity and mortality in these patient population.

\section{Abbreviations}

MetS, metabolic syndrome; IPT, intensive periodontal treatment; MPT, minimal periodontal treatment; hsCRP, high sensitivity C reactive protein; ITT, intention-to-treat; PP, per protocol; IL, interleukin; TNF, tumor necrosis factor, HbA1c, glycated haemoglobin, CVD, cardiovascular disease; HOMA, homeostasis model assessment; WC, waist circumference; BMI, body mass index; FPG, fasting plasma glucose; HDL, high density lipoprotein; LDL, low density lipoprotein; PIl, plaque index; CAL, Clinical attachment level; PPD, probing pocket depth, BOP, bleeding on probing; SRP, scaling and root planning; RTF, reduced transport fluid; EDTA, ethylenediaminetetraacetic acid; LOCF, last observation carried forward.

\section{Declarations}

\section{Acknowledgements}

Not applicable.

\section{Authors'contributions}

All authors contributed significantly to this work. MS, DH and AZ conceived the study. EM, ML, HV, MM, $\mathrm{JM}$ and LV contributed to data collection. Statistical analysis was carried out by EM. EM drafted the manuscript. All authors critically revised the manuscript and approved the final version.

\section{Funding}

This study was partially supported by Colgate-Palmolive through a research contract with the University Complutense of Madrid (Spain). The authors were fully independent in preparing the protocol, conducting the research, interpreting the result and preparing the manuscript.

\section{Availability of data and materials}

The datasets used and/or analyzed during the current study are available from the corresponding author on reasonable request.

\section{Ethics approval and consent to participate}


All participants gave their informed consent. The protocol of this investigation was reviewed and approved by the institutional ethic committee (Internal Code 12/206, Hospital Clínico de San Carlos, Madrid).

Consent for publication

Not applicable

Competing interests

All authors declare that they have no conflict of interests.

\section{References}

1. Eckel RH, Grundy SM, Zimmet PZ: The metabolic syndrome. Lancet 2005, 365(9468):1415-1428.

2. Grundy SM: Metabolic syndrome pandemic. Arterioscler Thromb Vasc Biol 2008, 28(4):629-636.

3. Gami AS, Witt BJ, Howard DE, Erwin PJ, Gami LA, Somers VK, Montori VM: Metabolic syndrome and risk of incident cardiovascular events and death: a systematic review and meta-analysis of longitudinal studies. J Am Coll Cardiol 2007, 49(4):403-414.

4. van Vliet-Ostaptchouk JV, Nuotio M-L, Slagter SN, Doiron D, Fischer K, Foco L, Gaye A, Gögele M, Heier M, Hiekkalinna $T$ et al: The prevalence of metabolic syndrome and metabolically healthy obesity in Europe: a collaborative analysis of ten large cohort studies. BMC endocrine disorders 2014, 14(1):9-13.

5. Martinez-Larrad MT, Corbaton-Anchuelo A, Fernandez-Perez C, Lazcano-Redondo Y, Escobar-Jimenez F, Serrano-Rios M: Metabolic syndrome, glucose tolerance categories and the cardiovascular risk in Spanish population. Diabetes Res Clin Pract 2016, 114:23-31.

6. Mozumdar A, Liguori G: Persistent increase of prevalence of metabolic syndrome among U.S. adults: NHANES III to NHANES 1999-2006. Diabetes Care 2011, 34(1):216-219.

7. Collaborators GBDOD, Bernabe E, Marcenes W, Hernandez CR, Bailey J, Abreu LG, Alipour V, Amini S, Arabloo J, Arefi $Z$ et al: Global, Regional, and National Levels and Trends in Burden of Oral Conditions from 1990 to 2017: A Systematic Analysis for the Global Burden of Disease 2017 Study. J Dent Res 2020, 99(4):362-373.

8. Dietrich T, Sharma P, Walter C, Weston P, Beck J: The epidemiological evidence behind the association between periodontitis and incident atherosclerotic cardiovascular disease. $J$ Clin Periodontol 2013, 40 Suppl 14:S70-84.

9. Paraskevas S, Huizinga JD, Loos BG: A systematic review and meta-analyses on C-reactive protein in relation to periodontitis. J Clin Periodontol 2008, 35(4):277-290.

10. Reyes L, Herrera D, Kozarov E, Roldan S, Progulske-Fox A: Periodontal bacterial invasion and infection: contribution to atherosclerotic pathology. J Clin Periodontol 2013, 40 Suppl 14:S30-50. 
11. Morita T, Yamazaki Y, Mita A, Takada K, Seto M, Nishinoue N, Sasaki Y, Motohashi M, Maeno M: A cohort study on the association between periodontal disease and the development of metabolic syndrome. Journal of periodontology 2010, 81(4):512-519.

12. D'Aiuto F, Sabbah W, Netuveli G, Donos N, Hingorani AD, Deanfield J, Tsakos G: Association of the metabolic syndrome with severe periodontitis in a large U.S. population-based survey. J Clin Endocrinol Metab 2008, 93(10):3989-3994.

13. Li P, He L, Sha Y-Q, Luan Q-X: Relationship of metabolic syndrome to chronic periodontitis. Journal of periodontology 2009, 80(4):541-549.

14. Benguigui C, Bongard V, Ruidavets J-B, Chamontin B, Sixou M, Ferrières J, Amar J: Metabolic syndrome, insulin resistance, and periodontitis: a cross-sectional study in a middle-aged French population. Journal of Clinical Periodontology 2010, 37(7):601-608.

15. Nibali L, Tatarakis N, Needleman I, Tu YK, D'Aiuto F, Rizzo M, Donos N: Clinical review: Association between metabolic syndrome and periodontitis: a systematic review and meta-analysis. J Clin Endocrinol Metab 2013, 98(3):913-920.

16. Chapple IL, Matthews JB: The role of reactive oxygen and antioxidant species in periodontal tissue destruction. Periodontol 2000 2007, 43:160-232.

17. Bullon P, Morillo JM, Ramirez-Tortosa MC, Quiles JL, Newman HN, Battino M: Metabolic syndrome and periodontitis: is oxidative stress a common link? J Dent Res 2009, 88(6):503-518.

18. D'Aiuto F, Nibali L, Parkar M, Patel K, Suvan J, Donos N: Oxidative stress, systemic inflammation, and severe periodontitis. J Dent Res 2010, 89(11):1241-1246.

19. Pink C, Kocher T, Meisel P, Dörr M, Markus MRP, Jablonowski L, Grotevendt A, Nauck M, Holtfreter B: Longitudinal effects of systemic inflammation markers on periodontitis. J Clin Periodonto/2015, 42(11):988-997.

20. D'Aiuto F, Nibali L, Parkar M, Suvan J, Tonetti MS: Short-term effects of intensive periodontal therapy on serum inflammatory markers and cholesterol. Journal of dental research 2005, 84(3):269-273.

21. Shimada Y, Komatsu Y, Ikezawa-Suzuki I, Tai H, Sugita N, Yoshie H: The effect of periodontal treatment on serum leptin, interleukin-6, and C-reactive protein. Journal of Periodontology 2010 , 81(8):1118-1123.

22. Almaghlouth AA, Cionca N, Cancela JA, Décaillet F, Courvoisier DS, Giannopoulou C, Mombelli A: Effect of periodontal treatment on peak serum levels of inflammatory markers. Clin Oral Investig 2014, 18(9):2113-2121.

23. López NJ, Quintero A, Casanova PA, Ibieta Cl, Baelum V, López R: Effects of periodontal therapy on systemic markers of inflammation in patients with metabolic syndrome: a controlled clinical trial. Journal of Periodontology 2012, 83(3):267-278.

24. Torumtay G, Kırzıoğlu FY, Öztürk Tonguç M, Kale B, Calapoğlu M, Orhan H: Effects of periodontal treatment on inflammation and oxidative stress markers in patients with metabolic syndrome. Journal of periodontal research 2016, 51(4):489-498. 
25. Yamazaki K, Honda T, Oda T, Ueki-Maruyama K, Nakajima T, Yoshie H, Seymour GJ: Effect of periodontal treatment on the C-reactive protein and proinflammatory cytokine levels in Japanese periodontitis patients. Journal of periodontal research 2005, 40(1):53-58.

26. Behle JH, Sedaghatfar MH, Demmer RT, Wolf DL, Celenti R, Kebschull M, Belusko PB, Herrera-Abreu M, Lalla E, Papapanou PN: Heterogeneity of systemic inflammatory responses to periodontal therapy. J Clin Periodonto/2009, 36(4):287-294.

27. Alberti KGMM, Eckel RH, Grundy SM, Zimmet PZ, Cleeman JI, Donato KA, Fruchart J-C, James WPT, Loria CM, Smith SC et al: Harmonizing the metabolic syndrome: a joint interim statement of the International Diabetes Federation Task Force on Epidemiology and Prevention; National Heart, Lung, and Blood Institute; American Heart Association; World Heart Federation; International Atherosclerosis Society; and International Association for the Study of Obesity. In: Circulation. vol. 120: American Heart Association, Inc.; 2009: 1640-1645.

28. Papapanou PN, Sanz M, Buduneli N, Dietrich T, Feres M, Fine DH, Flemmig TF, Garcia R, Giannobile WV, Graziani F et al: Periodontitis: Consensus report of workgroup 2 of the 2017 World Workshop on the Classification of Periodontal and Peri-Implant Diseases and Conditions. J Clin Periodonto/ 2018, 45 Suppl 20:S162-S170.

29. Koromantzos PA, Makrilakis K, Dereka X, Katsilambros N, Vrotsos IA, Madianos PN: A randomized, controlled trial on the effect of non-surgical periodontal therapy in patients with type 2 diabetes. Part I: effect on periodontal status and glycaemic control. J Clin Periodontol 2011, 38(2):142-147.

30. Tonetti MS, Claffey N, European Workshop in Periodontology group C: Advances in the progression of periodontitis and proposal of definitions of a periodontitis case and disease progression for use in risk factor research. Group $\mathrm{C}$ consensus report of the 5th European Workshop in Periodontology. $J$ Clin Periodontol 2005, 32 Suppl 6:210-213.

31. Silness J, Loe H: Periodontal Disease in Pregnancy. Ii. Correlation between Oral Hygiene and Periodontal Condtion. Acta Odontol Scand 1964, 22:121-135.

32. Loe H, Silness J: Periodontal Disease in Pregnancy. I. Prevalence and Severity. Acta Odontol Scand 1963, 21:533-551.

33. Syed SA, Loesche WJ, Pape HL, Jr., grenier E: Predominant cultivable flora isolated from human root surface caries plaque. Infect Immun 1975, 11(4):727-731.

34. Ridker PM, MacFadyen JG, Everett BM, Libby P, Thuren T, Glynn RJ, Group CT: Relationship of Creactive protein reduction to cardiovascular event reduction following treatment with canakinumab: a secondary analysis from the CANTOS randomised controlled trial. Lancet 2018, 391(10118):319328.

35. Lopez NJ, Quintero A, Casanova PA, Ibieta Cl, Baelum V, Lopez R: Effects of periodontal therapy on systemic markers of inflammation in patients with metabolic syndrome: a controlled clinical trial. $J$ Periodontol 2012, 83(3):267-278.

36. Demmer RT, Trinquart L, Zuk A, Fu BC, Blomkvist J, Michalowicz BS, Ravaud P, Desvarieux M: The influence of anti-infective periodontal treatment on C-reactive protein: a systematic review and meta- 
analysis of randomized controlled trials. PLOS One 2013, 8(10):e77441.

37. Bokhari SA, Khan AA, Butt AK, Azhar M, Hanif M, Izhar M, Tatakis DN: Non-surgical periodontal therapy reduces coronary heart disease risk markers: a randomized controlled trial. $J$ Clin Periodontol 2012, 39(11):1065-1074.

38. Chen L, Luo G, Xuan D, Wei B, Liu F, Li J, Zhang J: Effects of non-surgical periodontal treatment on clinical response, serum inflammatory parameters, and metabolic control in patients with type 2 diabetes: a randomized study. Journal of Periodontology 2012, 83(4):435-443.

39. Teeuw WJ, Slot DE, Susanto H, Gerdes VEA, Abbas F, D\&apos;Aiuto F, Kastelein JJP, Loos BG: Treatment of periodontitis improves the atherosclerotic profile: a systematic review and metaanalysis. J Clin Periodontol 2014, 41(1):70-79.

40. D’Aiuto F, Gkranias N, Bhowruth D, Khan T, Orlandi M, Suvan J, Masi S, Tsakos G, Hurel S, Hingorani $A D$ et al: Systemic effects of periodontitis treatment in patients with type 2 diabetes: a 12 month, single-centre, investigator-masked, randomised trial. The lancet Diabetes \&amp; endocrinology 2018, 6(12):954-965.

41. Montenegro MM, Ribeiro IWJ, Kampits C, Saffı MAL, Furtado MV, Polanczyk CA, Haas AN, Rösing CK: Randomized controlled trial of the effect of periodontal treatment on cardiovascular risk biomarkers in patients with stable coronary artery disease: Preliminary findings of 3 months. J Clin Periodontol 2019, 46(3):321-331.

42. Desvarieux M, Demmer RT, Rundek T, Boden-Albala B, Jacobs DR, Sacco RL, Papapanou PN: Periodontal microbiota and carotid intima-media thickness: the Oral Infections and Vascular Disease Epidemiology Study (INVEST). Circulation 2005, 111(5):576-582.

43. Noack B, Genco RJ, Trevisan M, Grossi S, Zambon JJ, De Nardin E: Periodontal infections contribute to elevated systemic C-reactive protein level. J Periodontol 2001, 72(9):1221-1227.

44. Tuomisto K, Jousilahti P, Sundvall J, Pajunen P, Salomaa V: C-reactive protein, interleukin-6 and tumor necrosis factor alpha as predictors of incident coronary and cardiovascular events and total mortality. A population-based, prospective study. Thromb Haemost 2006, 95(3):511-518.

45. Demmer RT, Desvarieux M, Holtfreter B, Jacobs DR, Jr., Wallaschofski H, Nauck M, Volzke H, Kocher $\mathrm{T}$ : Periodontal status and A1C change: longitudinal results from the study of health in Pomerania (SHIP). Diabetes Care 2010, 33(5):1037-1043.

46. Tonetti MS, D'Aiuto F, Nibali L, Donald A, Storry C, Parkar M, Suvan J, Hingorani AD, Vallance P, Deanfield J: Treatment of periodontitis and endothelial function. N Eng/ J Med 2007, 356(9):911-920.

47. Zhou Q-B, Xia W-H, Ren J, Yu B-B, Tong X-Z, Chen Y-B, Chen S, Feng L, Dai J, Tao J et al: Effect of Intensive Periodontal Therapy on Blood Pressure and Endothelial Microparticles in Patients With Prehypertension and Periodontitis: A Randomized Controlled Trial. Journal of Periodontology 2017, 88(8):711-722.

48. Muñoz Aguilera E, Suvan J, Buti J, Czesnikiewicz-Guzik M, Barbosa Ribeiro A, Orlandi M, Guzik TJ, Hingorani AD, Nart J, D\&apos;Aiuto F: Periodontitis is associated with hypertension: a systematic review and meta-analysis. Cardiovascular research 2020, 116(1):28-39. 
49. Law MR, Morris JK, Wald NJ: Use of blood pressure lowering drugs in the prevention of cardiovascular disease: meta-analysis of 147 randomised trials in the context of expectations from prospective epidemiological studies. BMJ 2009, 338:b1665.

50. Joffres M, Falaschetti E, Gillespie C, Robitaille C, Loustalot F, Poulter N, McAlister FA, Johansen H, Baclic $\mathrm{O}$, Campbell $\mathrm{N}$ : Hypertension prevalence, awareness, treatment and control in national surveys from England, the USA and Canada, and correlation with stroke and ischaemic heart disease mortality: a cross-sectional study. BMJ Open 2013, 3(8):e003423.

51. Anderson JL, Muhlestein JB, Carlquist J, Allen A, Trehan S, Nielson C, Hall S, Brady J, Egger M, Horne $B$ et al: Randomized secondary prevention trial of azithromycin in patients with coronary artery disease and serological evidence for Chlamydia pneumoniae infection: The Azithromycin in Coronary Artery Disease: Elimination of Myocardial Infection with Chlamydia (ACADEMIC) study. Circulation 1999, 99(12):1540-1547.

52. Teughels W, Feres M, Oud V, Martin C, Matesanz P, Herrera D: Adjunctive effect of systemic antimicrobials in periodontitis therapy. A systematic review and meta-analysis. $J$ Clin Periodontol 2020.

53. Yousuf O, Mohanty BD, Martin SS, Joshi PH, Blaha MJ, Nasir K, Blumenthal RS, Budoff MJ: Highsensitivity C-reactive protein and cardiovascular disease: a resolute belief or an elusive link? J Am Coll Cardiol 2013, 62(5):397-408.

54. Greenland P, Alpert JS, Beller GA, Benjamin EJ, Budoff MJ, Fayad ZA, Foster E, Hlatky MA, Hodgson JM, Kushner FG et al: 2010 ACCF/AHA guideline for assessment of cardiovascular risk in asymptomatic adults: a report of the American College of Cardiology Foundation/American Heart Association Task Force on Practice Guidelines. Circulation 2010, 122(25):e584-636.

55. Perk J, De Backer G, Gohlke H, Graham I, Reiner Z, Verschuren M, Albus C, Benlian P, Boysen G, Cifkova $\mathrm{R}$ et al: European Guidelines on cardiovascular disease prevention in clinical practice (version 2012). The Fifth Joint Task Force of the European Society of Cardiology and Other Societies on Cardiovascular Disease Prevention in Clinical Practice (constituted by representatives of nine societies and by invited experts). Eur Heart J 2012, 33(13):1635-1701.

56. Cook NR, Buring JE, Ridker PM: The effect of including C-reactive protein in cardiovascular risk prediction models for women. Ann Intern Med 2006, 145(1):21-29.

\section{Tables}

Table 1. Baseline characteristics of the intention-to-treat population with metabolic syndrome (MetS). 


\begin{tabular}{|c|c|c|c|}
\hline Variable $^{\mathrm{a}}$ & Intensive Periodontal Therapy $(n=32)$ & Minimal Periodontal Therapy $(n=31)$ & p value \\
\hline & $56.7(6.5)$ & $58.3(5.8)$ & 0.319 \\
\hline & & & 0.839 \\
\hline Male (\%) & $22(68.8 \%)$ & $22(70.9 \%)$ & \\
\hline Female (\%) & $10(31.2 \%)$ & $9(29.1 \%)$ & \\
\hline ; & & & 0.112 \\
\hline Never smoker $(\%)$ & $15(46.9 \%)$ & $11(35.5 \%)$ & \\
\hline Former smoker $(\%)$ & $9(28.1 \%)$ & $17(54.8 \%)$ & \\
\hline Current Smoker (\%) & $8(25.0 \%)$ & $3(9.7 \%)$ & \\
\hline $\mathrm{x}\left(\mathrm{BMI} ; \mathrm{kg} / \mathrm{m}^{2}\right)$ & $39.1(5.6)$ & $38.0(4.7)$ & 0.618 \\
\hline rence $(\mathrm{WC})(\mathrm{cm})$ & $120.1(18.4)$ & $119.0(9.1)$ & 0.848 \\
\hline \multicolumn{4}{|l|}{ (BP; mm Hg) } \\
\hline Systolic BP (mm Hg) & $148.1(21.5)$ & $138.6(18.3)$ & 0.112 \\
\hline Diastolic BP (mm Hg) & $91.3(18.2)$ & $84.1(11.2)$ & 0.143 \\
\hline ein (CRP; mg/L) & $\begin{array}{c}3.9(2.9) \\
2.8(\text { IQR } 1.5-4.9) \\
\end{array}$ & $\begin{array}{c}3.9(3.4) \\
2.4 \text { (IQR 1.4-4.9) } \\
\end{array}$ & 0.831 \\
\hline th CRP levels $\geq 3$ mg/L (\%) & $17(53.1 \%)$ & $17(54.8 \%)$ & 0.975 \\
\hline$(\mathrm{mg} / \mathrm{dL})$ & $145.6(29.7)$ & $138.5(28.1)$ & 0.369 \\
\hline (dL) & $419.7(108.7)$ & $398.5(89.1)$ & 0.259 \\
\hline$\underline{l}$ count $(\mathrm{WBC} ; \mathrm{K} / \mu \mathrm{L})$ & $7.8(1.9)$ & $7.5(1.7)$ & 0.445 \\
\hline \multicolumn{4}{|l|}{ 1ediators in serum $(\mathrm{pg} / \mathrm{mL})$} \\
\hline IL-1 $\beta$ & $1.5(0.9)$ & $1.9(1.2)$ & 0.161 \\
\hline IL-6 & $\begin{array}{c}2.2(1.8) \\
1.9(\text { IQR 1.3-2.3) } \\
\end{array}$ & $\begin{array}{c}2.8(1.9) \\
2.8 \text { (IQR 1.4-3.9) } \\
\end{array}$ & 0.178 \\
\hline IL-8 & $\begin{array}{c}6.9(9.7) \\
3.3 \text { (IQR 2.3-5.7) } \\
\end{array}$ & $\begin{array}{c}5.4(3.0) \\
4.7 \text { (IQR 3.5-6.3) } \\
\end{array}$ & 0.105 \\
\hline \multirow[t]{2}{*}{ TNF- $\alpha$} & $\begin{array}{c}7.9(6.2) \\
5.7 \text { (IQR 4.8-10.2) } \\
\end{array}$ & $\begin{array}{c}8.7(8.6) \\
6.3 \text { (IQR 4.1-8.9) } \\
\end{array}$ & 0.957 \\
\hline & $\begin{array}{c}6.3(1.2) \\
6.1 \text { (IQR 5.5-6.9) } \\
\end{array}$ & $\begin{array}{c}6.0(1.0) \\
5.7 \text { (IQR 5.2-6.5) } \\
\end{array}$ & 0.328 \\
\hline ects with HbA1c $\geq 7 \%$ (\%) & $10(31.25 \%)$ & $8(25.8 \%)$ & 0.774 \\
\hline Glucose (FPG; mg/dL) & $\begin{array}{c}128.6(30.3) \\
125 \text { (IQR 107-154) } \\
\end{array}$ & $\begin{array}{c}133.0(51.7) \\
112 \text { (IQR 97-159) } \\
\end{array}$ & 0.500 \\
\hline (mIU/L) & $\begin{array}{c}19.3(10.8) \\
18.7 \text { (IQR 12.3-27.6) } \\
\end{array}$ & $\begin{array}{c}14.5(9.3) \\
11.1 \text { (IQR 9.4-15.8) } \\
\end{array}$ & 0.033 \\
\hline unction & $104.8(69.0)$ & $92.7(50.6)$ & 0.519 \\
\hline sensitivity & $\begin{array}{c}59.0(55.3) \\
38.3 \text { (IQR 30.0-62.3) } \\
\end{array}$ & $\begin{array}{c}62.6(28.0) \\
66.5(\text { IQR 43.3-75.1) } \\
\end{array}$ & 0.061 \\
\hline resistance & $\begin{array}{c}2.6(1.4) \\
2.6 \text { (IQR 1.6-3.3) } \\
\end{array}$ & $\begin{array}{c}2.0(1.2) \\
1.5 \text { (IQR 1.3-2.3) } \\
\end{array}$ & 0.063 \\
\hline ol (mg/dL) & $174.8(34.7)$ & $189.4(48.4)$ & 0.203 \\
\hline $\mathrm{l}(\mathrm{mg} / \mathrm{dL})$ & $46.1(13.3)$ & $46.9(12.4)$ & 0.858 \\
\hline $\mathrm{l}(\mathrm{mg} / \mathrm{dL})$ & $114.3(34.7)$ & $105.7(44.9)$ & 0.535 \\
\hline [G; mg/dL) & $129.5(52.3)$ & $136.6(42.5)$ & 0.582 \\
\hline (dL) & $\begin{array}{c}0.9(0.5) \\
0.8 \text { (IQR 0.7-0.9) }\end{array}$ & $\begin{array}{c}0.9(0.3) \\
0.9 \text { (IQR 0.8-1.0) }\end{array}$ & 0.461 \\
\hline
\end{tabular}

a Data are mean (standard deviation, SD), n (\%), or median (interquartile range, IQR).

HOMA2, Homeostasis Model Assessment 2.

Table 2. Periodontal parameters in both groups over time. 


\begin{tabular}{|c|c|c|c|c|c|c|c|c|c|c|}
\hline \multirow[t]{2}{*}{ Variable } & \multicolumn{2}{|c|}{ Baseline (BL) } & \multicolumn{2}{|c|}{3 months (3M) } & \multicolumn{2}{|c|}{$\Delta \mathrm{BL}-3 \mathrm{M}$} & \multicolumn{2}{|c|}{6 months $(6 \mathrm{M})$} & \multicolumn{2}{|c|}{$\Delta \mathrm{BL}-6 \mathrm{M}$} \\
\hline & $\begin{array}{c}\text { Mean } \\
(\mathrm{SD})\end{array}$ & $\begin{array}{c}\mathrm{p} \\
\text { value }\end{array}$ & $\begin{array}{c}\text { Mean } \\
(\mathrm{SD})\end{array}$ & $\begin{array}{c}\mathrm{p} \\
\text { value }\end{array}$ & $\begin{array}{c}\text { Mean } \\
(\mathrm{SD})\end{array}$ & $\begin{array}{c}\mathrm{p} \\
\text { value }\end{array}$ & $\begin{array}{c}\text { Mean } \\
(\mathrm{SD})\end{array}$ & $\begin{array}{c}\mathrm{p} \\
\text { value }\end{array}$ & $\begin{array}{c}\text { Mean } \\
(\mathrm{SD})\end{array}$ & $\begin{array}{c}\mathrm{p} \\
\text { value }\end{array}$ \\
\hline \multicolumn{11}{|l|}{$(0-3)$} \\
\hline IPT Group & $1.8(0.4)$ & \multirow[t]{2}{*}{0.444} & $0.8(0.3)^{*}$ & \multirow[t]{2}{*}{0.002} & $1.0(0.5)$ & \multirow[t]{2}{*}{0.012} & $0.8(0.3)^{*}$ & \multirow[t]{2}{*}{0.003} & $\begin{array}{c}1.0 \\
(0.4) \\
\end{array}$ & \multirow[t]{2}{*}{0.013} \\
\hline MPT Group & $1.9(0.5)$ & & $1.3(0.7)^{*}$ & & $0.6(0.6)$ & & $1.2(0.6)^{*}$ & & $\begin{array}{c}0.7 \\
(0.5) \\
\end{array}$ & \\
\hline \multicolumn{11}{|l|}{$x(0-3)$} \\
\hline IPT Group & $1.8(0.4)$ & \multirow[t]{2}{*}{0.091} & $0.6(0.2)^{*}$ & \multirow[t]{2}{*}{$<0.001$} & $1.2(0.5)$ & \multirow[t]{2}{*}{$<0.001$} & $0.6(0.3)^{*}$ & \multirow[t]{2}{*}{$<0.001$} & $\begin{array}{c}1.1 \\
(0.5) \\
\end{array}$ & \multirow[t]{2}{*}{$<0.001$} \\
\hline MPT Group & $2.0(0.4)$ & & $1.4(0.7)^{*}$ & & $0.6(0.6)$ & & $1.4(0.6)^{*}$ & & $\begin{array}{c}0.5 \\
(0.5) \\
\end{array}$ & \\
\hline \multicolumn{11}{|l|}{ Bleeding Score (\%) } \\
\hline IPT Group & $\begin{array}{c}59.8 \% \\
(20) \\
\end{array}$ & \multirow[t]{2}{*}{0.139} & $\begin{array}{c}24.9 \% \\
(17)^{*}\end{array}$ & \multirow[t]{2}{*}{$<0.001$} & $\begin{array}{c}32.8 \% \\
(21) \\
\end{array}$ & \multirow[t]{2}{*}{0.025} & $\begin{array}{c}20.5 \% \\
(11)^{*}\end{array}$ & \multirow[t]{2}{*}{$<0.001$} & $\begin{array}{c}37.6 \% \\
(17) \\
\end{array}$ & \multirow[t]{2}{*}{$<0.001$} \\
\hline MPT Group & $\begin{array}{c}67.8 \% \\
(20) \\
\end{array}$ & & $\begin{array}{c}48.4 \% \\
(21)^{*}\end{array}$ & & $\begin{array}{c}19.4 \% \\
(20) \\
\end{array}$ & & $\begin{array}{c}51.6 \% \\
(18) \\
\end{array}$ & & $\begin{array}{c}16.1 \% \\
(21) \\
\end{array}$ & \\
\hline \multicolumn{11}{|l|}{ sntal Pocket Depth } \\
\hline IPT Group & $3.7(0.9)$ & \multirow[t]{2}{*}{0.747} & $2.7(0.3)^{*}$ & \multirow[t]{2}{*}{$<0.001$} & $1.1(0.6)$ & \multirow[t]{2}{*}{$<0.001$} & $2.6(0.3)^{*}$ & \multirow[t]{2}{*}{$<0.001$} & $\begin{array}{c}1.2 \\
(0.6) \\
\end{array}$ & \multirow[t]{2}{*}{$<0.001$} \\
\hline MPT Group & $3.8(0.9)$ & & $3.5(0.7)$ & & $0.3(0.8)$ & & $3.5(0.6)$ & & $\begin{array}{c}0.3 \\
(0.8) \\
\end{array}$ & \\
\hline \multicolumn{11}{|l|}{ f Periodontal Pockets } \\
\hline IPT Group & $\begin{array}{c}55.3 \% \\
(22) \\
\end{array}$ & 0.427 & $\begin{array}{c}13.9 \% \\
(12)^{*}\end{array}$ & $<0.001$ & $\begin{array}{c}39.4 \% \\
(20) \\
\end{array}$ & $<0.001$ & $\begin{array}{c}11.2 \% \\
(10)^{*}\end{array}$ & $<0.001$ & $\begin{array}{c}43.7 \% \\
(20) \\
\end{array}$ & $<0.001$ \\
\hline MPT Group & $\begin{array}{c}59.7 \% \\
(19) \\
\end{array}$ & & $\begin{array}{c}41.2 \% \\
(23)^{*}\end{array}$ & & $\begin{array}{c}18.5 \% \\
(18) \\
\end{array}$ & & $\begin{array}{c}43.9 \% \\
(21)^{*}\end{array}$ & & $\begin{array}{c}15.9 \% \\
(19) \\
\end{array}$ & \\
\hline f Periodontal Pockets & & & & & & & & & & \\
\hline IPT Group & $3.5 \%(6)$ & 0.739 & $0.1 \%(0)^{*}$ & 0.013 & $4.0 \%(6)$ & 0.007 & $\begin{array}{c}0.3 \% \\
(1)^{*}\end{array}$ & 0.016 & $\begin{array}{c}3.8 \% \\
(6) \\
\end{array}$ & 0.018 \\
\hline MPT Group & $4.1 \%(7)$ & & $3.6 \%(6)$ & & $0.6 \%(2)$ & & $3.3 \%(6)$ & & $\begin{array}{c}0.8 \% \\
(2) \\
\end{array}$ & \\
\hline Attachment Level & & & & & & & & & & \\
\hline IPT Group & $4.9(1.0)$ & 0.293 & $3.9(1.0)^{*}$ & 0.010 & $0.9(0.7)$ & 0.001 & $3.8(0.9)^{*}$ & 0.001 & $\begin{array}{c}1.0 \\
(0.8) \\
\end{array}$ & $<0.001$ \\
\hline MPT Group & $5.2(1.3)$ & & $4.8(1.4)$ & & $0.3(0.5)$ & & 4.9 (1.3) & & $\begin{array}{c}0.3 \\
(0.6) \\
\end{array}$ & \\
\hline eth & & & & & & & & & & \\
\hline IPT Group & $\begin{array}{l}22.6 \\
(3.8) \\
\end{array}$ & 0.611 & $21.9(4.1)$ & 0.944 & $0.7(1.5)$ & 0.130 & $\begin{array}{l}21.9 \\
(4.1) \\
\end{array}$ & 0.944 & $\begin{array}{c}0.7 \\
(1.5) \\
\end{array}$ & 0.130 \\
\hline MPT Group & $\begin{array}{l}22.0 \\
(4.2) \\
\end{array}$ & & $21.9(4.2)$ & & $0.2(0.5)$ & & $\begin{array}{l}21.9 \\
(4.2) \\
\end{array}$ & & $\begin{array}{c}0.2 \\
(0.5)\end{array}$ & \\
\hline
\end{tabular}

* Intra-group significant difference when compared to baseline $(\mathrm{p}<0.05)$

IPT, Intense Periodontal Therapy; MPT, Minimal Periodontal Therapy; SD, standard deviation.

Table 3. Inflammatory biomarkers and clinical variables 3 and 6 months after periodontal treatment, by study group. 


\begin{tabular}{|c|c|c|c|c|c|c|}
\hline \multirow[t]{2}{*}{ :iable } & \multicolumn{3}{|c|}{3 months (3M) } & \multicolumn{3}{|c|}{6 months $(6 \mathrm{M})$} \\
\hline & Mean (SE) or $n(\%)$ & $\begin{array}{c}\Delta 3 \mathrm{M} \\
(95 \% \mathrm{CI}) \\
\end{array}$ & $\mathrm{p}$ value & Mean (SE) or $\mathrm{n}(\%)$ & $\begin{array}{c}\Delta 6 \mathrm{M} \\
(95 \% \mathrm{CI}) \\
\end{array}$ & $\mathrm{p}$ value \\
\hline \multicolumn{7}{|l|}{$(\mathrm{CRP} ; \mathrm{mg} / \mathrm{L})$} \\
\hline IPT Group & $2.7(0.4)^{*}$ & \multirow{2}{*}{$\begin{array}{c}1.4 \\
(0.5,2.2) \\
\end{array}$} & \multirow[t]{2}{*}{0.001} & $2.9(0.4)^{*}$ & \multirow{2}{*}{$\begin{array}{c}1.2 \\
(0.4,2.0) \\
\end{array}$} & \multirow[t]{2}{*}{0.004} \\
\hline MPT Group & $3.9(0.6)$ & & & $4.0(0.8)$ & & \\
\hline \multicolumn{7}{|l|}{ ' levels $\geq 3 \mathrm{mg} / \mathrm{L}(\%)$} \\
\hline IPT Group & $13(40.6 \%)^{*}$ & \multirow{2}{*}{$\begin{array}{c}5.4 \\
(1.0,31.6) \\
\end{array}$} & \multirow[t]{2}{*}{0.040} & $14(43.8 \%)^{*}$ & \multirow{2}{*}{$\begin{array}{c}2.6 \\
(0.4,15.9) \\
\end{array}$} & \multirow[t]{2}{*}{0.312} \\
\hline MPT Group & $18(58.1 \%)$ & & & $18(58.1 \%)$ & & \\
\hline \multicolumn{7}{|l|}{$\mathrm{g} / \mathrm{dL})$} \\
\hline IPT Group & $138.4(6.2)$ & \multirow{2}{*}{$\begin{array}{c}-4.9 \\
(-15.6,5.8) \\
\end{array}$} & \multirow[t]{2}{*}{0.368} & $137.5(5.7)$ & \multirow{2}{*}{$\begin{array}{c}-6.9 \\
(-20.3,6.4) \\
\end{array}$} & \multirow[t]{2}{*}{0.308} \\
\hline MPT Group & $130.0(5.0))$ & & & $127.6(5.2)$ & & \\
\hline \multicolumn{7}{|l|}{ ) } \\
\hline IPT Group & $421.8(20.4)$ & \multirow{2}{*}{$\begin{array}{c}-27.4 \\
(-64.3,9.4) \\
\end{array}$} & \multirow[t]{2}{*}{0.144} & $419.6(21.8)$ & \multirow{2}{*}{$\begin{array}{c}-25.0 \\
(-66.6,16.5) \\
\end{array}$} & \multirow[t]{2}{*}{0.238} \\
\hline MPT Group & $398.3(17.9)$ & & & $400.5(16.1)$ & & \\
\hline \multicolumn{7}{|l|}{ ount (WBC; $K / \mu L)$} \\
\hline IPT Group & $7.5(0.4)$ & \multirow{2}{*}{$\begin{array}{c}-0.1 \\
(-0.7,0.5) \\
\end{array}$} & \multirow[t]{2}{*}{0.768} & $7.9(0.7)$ & \multirow{2}{*}{$\begin{array}{c}-0.4 \\
(-1.5,0.7) \\
\end{array}$} & \multirow[t]{2}{*}{0.515} \\
\hline MPT Group & $7.8(0.3)$ & & & $7.6(0.2)$ & & \\
\hline$\underline{\mathrm{L}})$ & & & & & & \\
\hline IPT Group & $0.9(0.1)^{*}$ & 1.2 & 0.046 & $1.5(0.2)$ & -0.1 & 0.601 \\
\hline MPT Group & $2.3(0.5)$ & $(0.0,2.4)$ & & $1.5(0.2)$ & $(-0.5,0.3)$ & \\
\hline -) & & & & & & \\
\hline IPT Group & $1.9(0.4)$ & 0.3 & 0.584 & $2.0(0.4)$ & 0.1 & 0.806 \\
\hline MPT Group & $2.6(0.4)$ & $(-0.8,1.3)$ & & $2.5(0.4)$ & $(-0.9,1.2)$ & \\
\hline -) & & & & & & \\
\hline IPT Group & $4.6(1.1)^{*}$ & 1.0 & 0.307 & $5.0(1.2)$ & 0.8 & 0.584 \\
\hline MPT Group & $5.4(0.8)$ & $(-0.9,2.8)$ & & $6.0(1.2)$ & $(-2.0,3.5)$ & \\
\hline (mL) & & & & & & \\
\hline IPT Group & $6.4(0.8)^{*}$ & 3.2 & 0.037 & $6.3(0.8)^{*}$ & 1.6 & 0.333 \\
\hline MPT Group & $10.0(2.3)$ & $(0.2,6.2)$ & & $8.2(1.4)$ & $(-1.6,4.8)$ & \\
\hline $\mathrm{BMI} ; \mathrm{kg} / \mathrm{m}^{2}$ ) & & & & & & \\
\hline IPT Group & 39.1 (1.6) & 0.1 & 0.503 & $39.2(1.6)$ & 0.0 & 0.611 \\
\hline MPT Group & $38.0(1.6)$ & $(-0.2,0.5)$ & & $38.0(1.6)$ & $(-0.1,0.2)$ & \\
\hline ice $(\mathrm{WC} ; \mathrm{cm})$ & & & & & & \\
\hline IPT Group & $120.1(4.5)$ & 0.2 & 0.527 & $120.1(4.6)$ & 0.4 & 0.115 \\
\hline MPT Group & $119.2(2.7)$ & $(-0.5,1.0)$ & & $119.2(2.7)$ & $(-0.1,1.0)$ & \\
\hline
\end{tabular}

Data are unadjusted mean and standard error (SE). $\mathrm{p}$ values are for the adjusted $\Delta$ values ( $\Delta 3 \mathrm{M}$ and $\Delta 6 \mathrm{M}$ ), that are adjusted for baseline values, age, sex, smoking habit and body mass index. In case of the percentage of subjects with CRP levels $\geq 3$ mg/L, the adjusted $\Delta$ values are expressed as odds ratios and 95\% confidence intervals (CI). Adjustment for BMI was made for baseline values, age, sex and smoking habit. * Intra-group significant difference when compared to baseline $(\mathrm{p}<0.05)$. IPT, Intense Periodontal Therapy; MPT, Minimal Periodontal Therapy; SIS, Summary Inflammatory Score; IL, interleukin; TNF, tumor necrosis factor

Table 4. Metabolic, vascular and renal measures at 3 and 6 months after periodontal treatment by study group. 


\begin{tabular}{|c|c|c|c|c|c|c|}
\hline \multirow[t]{2}{*}{ iable } & \multicolumn{3}{|c|}{3 months (3M) } & \multicolumn{3}{|c|}{6 months $(6 \mathrm{M})$} \\
\hline & Mean (SE) or $n(\%)$ & $\begin{array}{c}\Delta 3 \mathrm{M} \\
(95 \% \mathrm{CI})\end{array}$ & $\mathrm{p}$ value & Mean (SE) or $n(\%)$ & $\begin{array}{c}\Delta 6 \mathrm{M} \\
(95 \% \mathrm{CI})\end{array}$ & $\mathrm{p}$ value \\
\hline IPT Group & $5.9(0.1)^{*}$ & \multirow{2}{*}{$\begin{array}{c}0.3 \\
(0.1,0.6) \\
\end{array}$} & \multirow[t]{2}{*}{0.013} & $6.0(0.1)^{*}$ & \multirow{2}{*}{$\begin{array}{c}0.2 \\
(0.0,0.5) \\
\end{array}$} & \multirow[t]{2}{*}{0.110} \\
\hline MPT Group & $6.1(0.2)$ & & & $6.1(0.2)$ & & \\
\hline \multicolumn{7}{|l|}{$1 \mathrm{c} \geq 7 \%(\%)$} \\
\hline IPT Group & $6(18.8 \%)^{*}$ & \multirow{2}{*}{$\begin{array}{c}21.7 \\
(0.8-623.3) \\
\end{array}$} & \multirow[t]{2}{*}{0.073} & $9(28.1 \%)$ & \multirow{2}{*}{$\begin{array}{c}0.7 \\
(0.1-4.9) \\
\end{array}$} & \multirow[t]{2}{*}{0.739} \\
\hline MPT Group & $8(25.8 \%)$ & & & $7(22.6 \%)$ & & \\
\hline \multicolumn{7}{|l|}{ ucose (FPG; mg/dL) } \\
\hline IPT Group & $123.3(7.9)$ & \multirow{2}{*}{$\begin{array}{c}12.8 \\
(-3.0,28.6) \\
\end{array}$} & \multirow[t]{2}{*}{0.112} & $121.0(6.3)$ & \multirow{2}{*}{$\begin{array}{c}8.9 \\
(-9.2,26.9) \\
\end{array}$} & \multirow[t]{2}{*}{0.336} \\
\hline MPT Group & $130.0(8.8)$ & & & $130.5(9.7)$ & & \\
\hline \multicolumn{7}{|l|}{$\underline{\mathrm{U} / \mathrm{L})}$} \\
\hline IPT Group & $17.2(2.9)$ & \multirow{2}{*}{$\begin{array}{c}-1.4 \\
(-6.5,3.6) \\
\end{array}$} & \multirow[t]{2}{*}{0.583} & $14.3(2.1)$ & \multirow{2}{*}{$\begin{array}{c}1.3 \\
(-3.0,5.7) \\
\end{array}$} & \multirow[t]{2}{*}{0.548} \\
\hline MPT Group & $14.1(1.4)$ & & & $14.4(1.7)$ & & \\
\hline \multicolumn{7}{|l|}{ stion } \\
\hline IPT Group & $106.0(14.8)$ & \multirow{2}{*}{$\begin{array}{c}-13.6 \\
(-37.2,10.1) \\
\end{array}$} & 0.260 & $106.1(14.0)$ & 2.2 & 0.856 \\
\hline MPT Group & $87.2(10.6)$ & & & $100.4(11.9)$ & $(-21.6,26.0)$ & \\
\hline nsitivity & & & & & & \\
\hline IPT Group & $67.0(13.6)$ & -6.1 & 0.573 & $65.8(11.6)$ & -8.2 & 0.330 \\
\hline MPT Group & $57.9(5.4)$ & $(-27.3,15.1)$ & & $59.7(5.3)$ & $(-24.7,8.3)$ & \\
\hline sistance & & & & & & \\
\hline IPT Group & $2.3(0.4)$ & -0.2 & 0.666 & $2.2(0.3)$ & 0.0 & 0.940 \\
\hline MPT Group & $2.0(0.2)$ & $(-0.8,0.5)$ & & $2.0(0.2)$ & $(-0.6 .0 .6)$ & \\
\hline$(\mathrm{mg} / \mathrm{dL})$ & & & & & & \\
\hline IPT Group & $184.0(8.4)$ & -9.7 & 0.090 & $183.5(7.5)$ & -5.2 & 0.397 \\
\hline MPT Group & $180.6(8.1)$ & $(-20.9,1.5)$ & & $189.9(9.2)$ & $(-17.3,6.9)$ & \\
\hline$\underline{\mathrm{mg} / \mathrm{dL})}$ & & & & & & \\
\hline IPT Group & $46.2(3.8)$ & 0.8 & 0.858 & $47.2(2.7)$ & -4.0 & 0.097 \\
\hline MPT Group & $47.1(3.1)$ & $(-8.1,9.7)$ & & $48.4(2.7)$ & $(-8.8,0.7)$ & \\
\hline $\mathrm{mg} / \mathrm{dL})$ & & & & & & \\
\hline IPT Group & $109.6(8.5)$ & -5.7 & 0.327 & $107.6(6.6)$ & -2.2 & 0.779 \\
\hline MPT Group & $103.5(7.0)$ & $(-16.9,5.6)$ & & $107.5(8.3)$ & $(-17.9,13.4)$ & \\
\hline $\mathrm{mg} / \mathrm{dL})$ & & & & & & \\
\hline IPT Group & $136.5(9.7)$ & -0.2 & 0.984 & $125.6(9.7)$ & 1.2 & 0.895 \\
\hline MPT Group & $155.4(17.5)$ & $(-18.5,18.1)$ & & $131.7(8.3)$ & $(-16.5,18.9)$ & \\
\hline ssure (mm Hg) & & & & & & \\
\hline IPT Group & $136.4(3.0)^{*}$ & 7.3 & 0.008 & $136.4(2.8)$ & 4.7 & 0.574 \\
\hline MPT Group & $139.4(2.7)$ & $(1.9,12.6)$ & & $144.4(4.1)$ & $(-11.7,21.1)$ & \\
\hline ssure (mm Hg) & & & & & & \\
\hline IPT Group & $84.8(3.8)$ & 7.8 & 0.019 & $81.8(2.8)$ & 11.0 & 0.009 \\
\hline MPT Group & $89.6(5.4)$ & $(1.3,14.4)$ & & $86.9(1.8)$ & $(2.8,19.1)$ & \\
\hline ) & & & & & & \\
\hline IPT Group & $1.0(0.1)$ & 0.0 & 0.353 & $1.0(0.1)$ & 0.0 & 0.924 \\
\hline MPT Group & $0.9(0.1)$ & $(0.0,0.1)$ & & $1.0(0.1)$ & $(-0.1,0.1)$ & \\
\hline
\end{tabular}

Data are unadjusted mean and standard error (SE). $\mathrm{p}$ values are for the adjusted $\Delta$ values ( $\Delta 3 \mathrm{M}$ and $\Delta 6 \mathrm{M}$ ), that are adjusted for baseline values, age, sex, smoking habit and body mass index. In case of the proportions (\%), the adjusted $\Delta$ values are expressed as odds ratios and $95 \%$ confidence intervals (CI). * Intra-group significant difference when compared to baseline $(\mathrm{p}<0.05)$. IPT, Intense Periodontal Therapy; MPT, Minimal Periodontal Therapy; MetS, metabolic syndrome; HDL, high-density lipoproteins; LDL, low-density lipoproteins 
854 patients assessed for elegibility

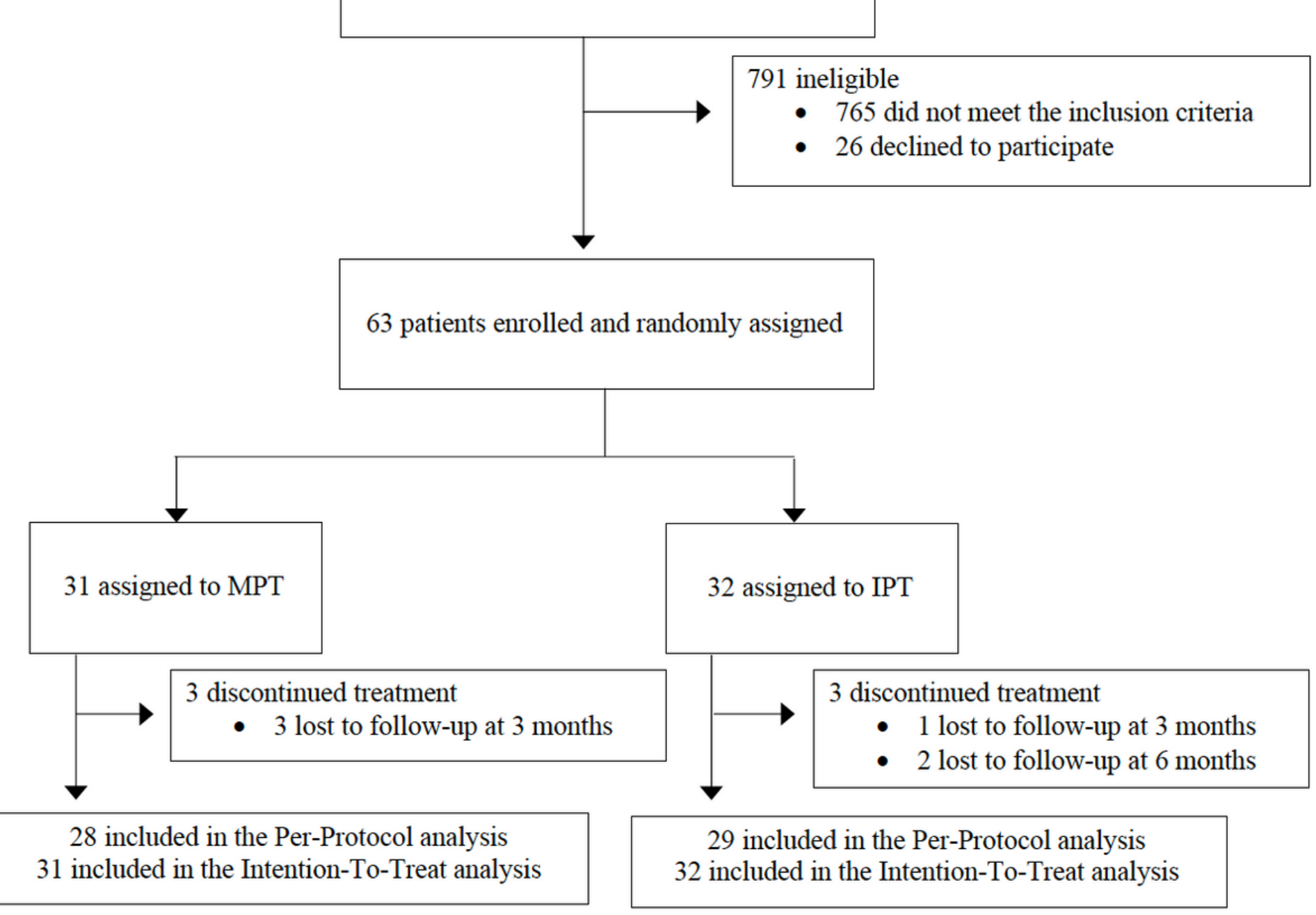

Figure 1

Flow-Chart of the Trial 


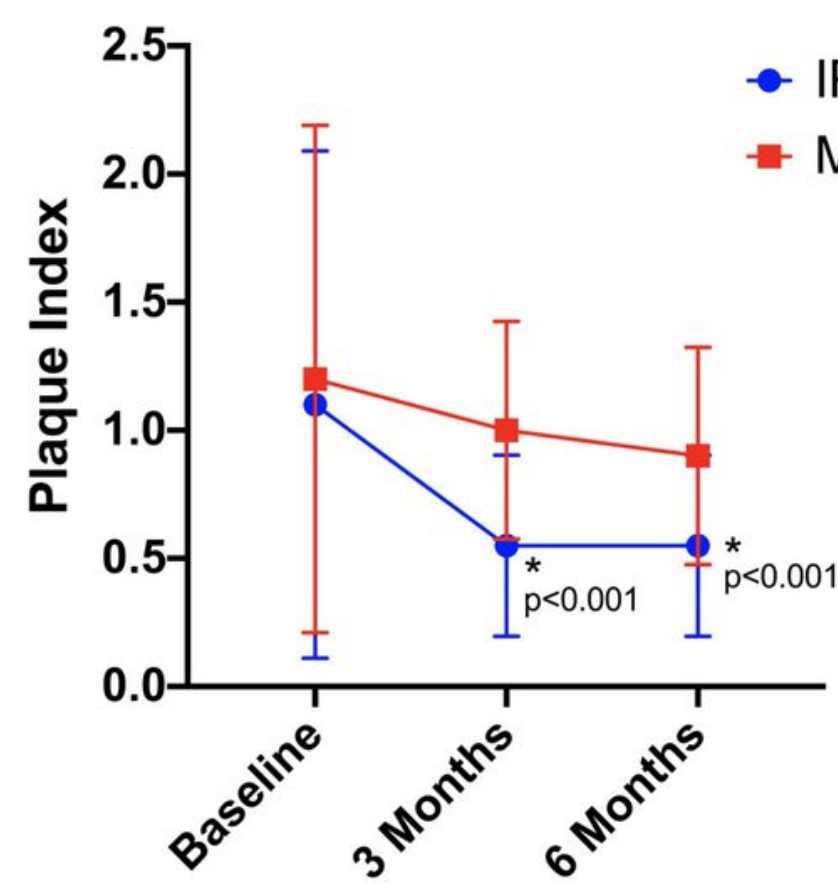

B)
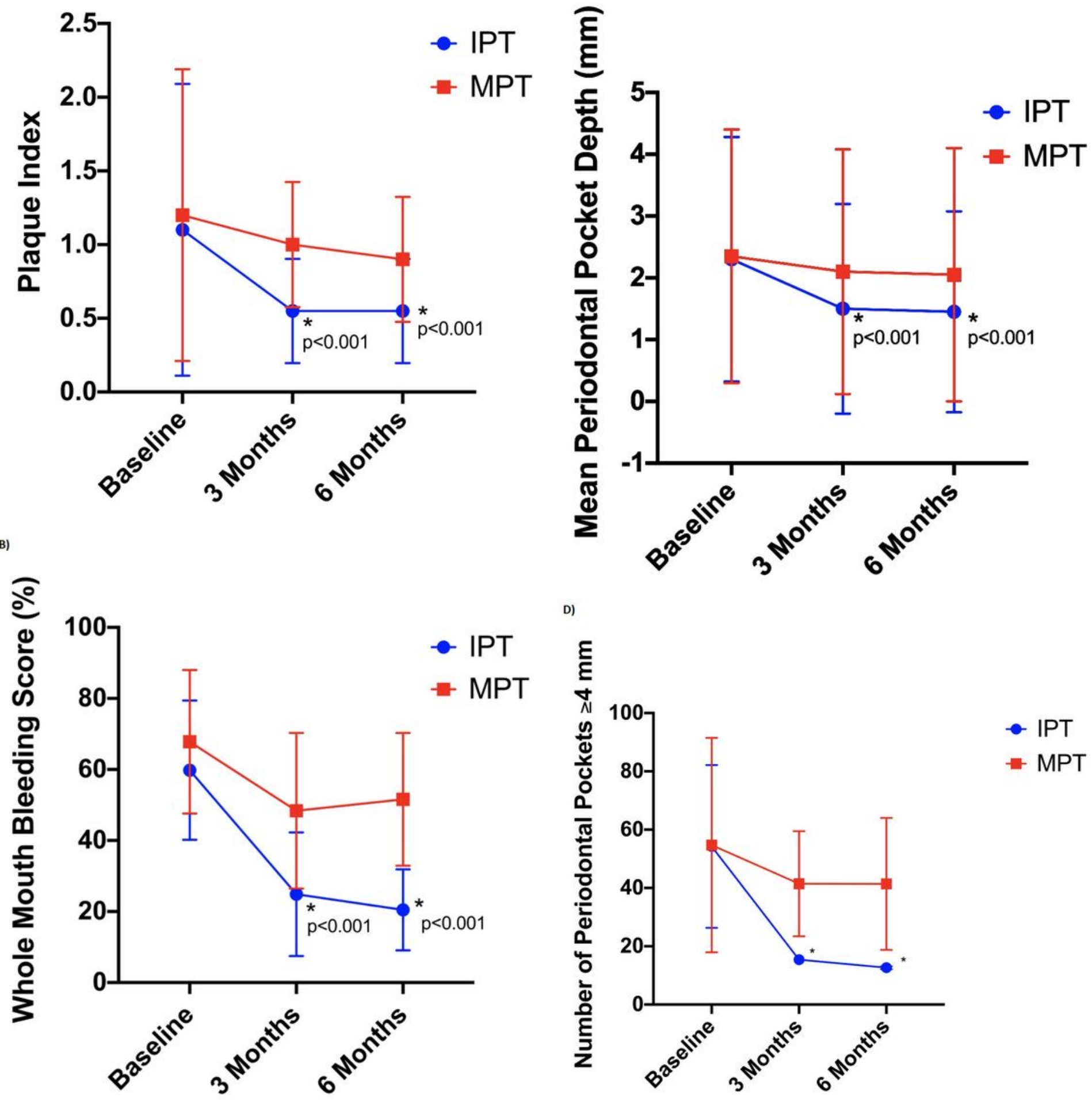

D)

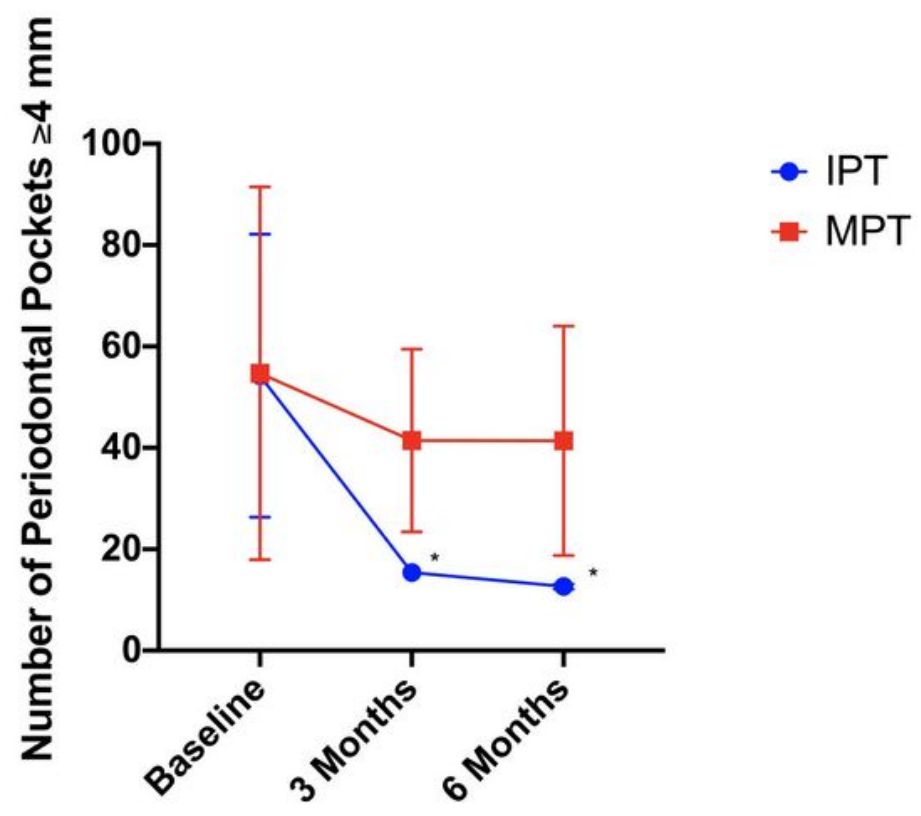

Figure 2

Periodontal measures at baseline and follow-up visits at 3 and 6 months. Data are unadjusted means and standard deviations (SDs). IPT, Intense Periodontal Therapy; MPT, Minimal Periodontal Therapy. * Between-groups differences were significant for all periodontal measures at 3 and 6 months $(p<0.01)$ 
A)

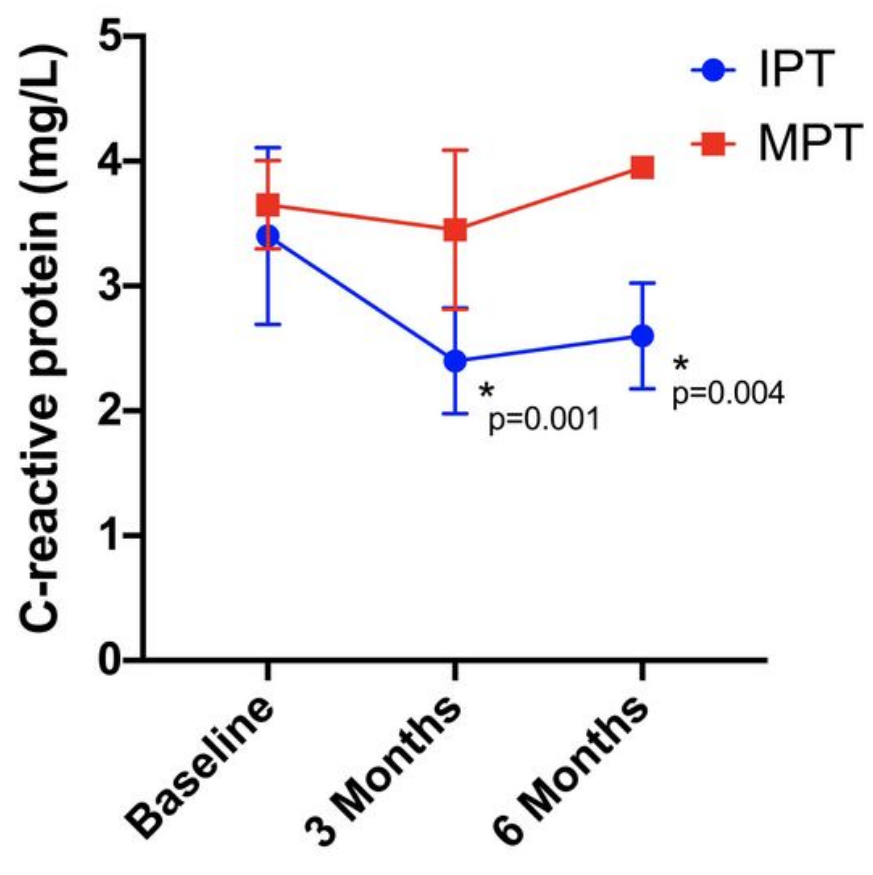

B)

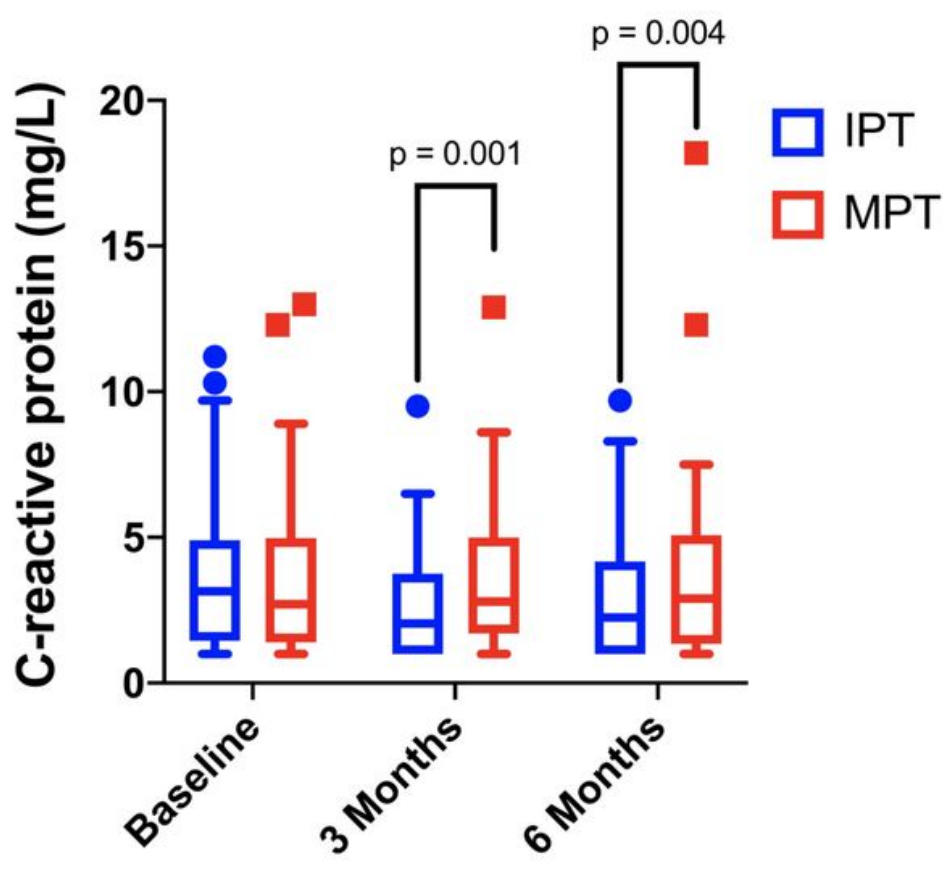

Figure 3

C-reactive Protein (CRP) during the 6-month study period. A) Data are unadjusted means and standard deviations (SDs). Adjusted p-values (for age, sex, smoking, baseline values and body mass index) for between-group difference at 3 and 6 months were $p=0.001$ and $p=0.004$, respectively. B) Boxplot showing CRP concentrations over visits by study group. Values are presented as median, $25 \%$ and $75 \%$ quantiles, whiskers corresponding to minimum and maximum values within the interval [ $25 \%$ quantile $-1.5 \mathrm{x}$ interquartile range, $75 \%+1.5 \mathrm{x}$ interquartile range], and outliers. IPT, Intense Periodontal Therapy; MPT, Minimal Periodontal Therapy. 

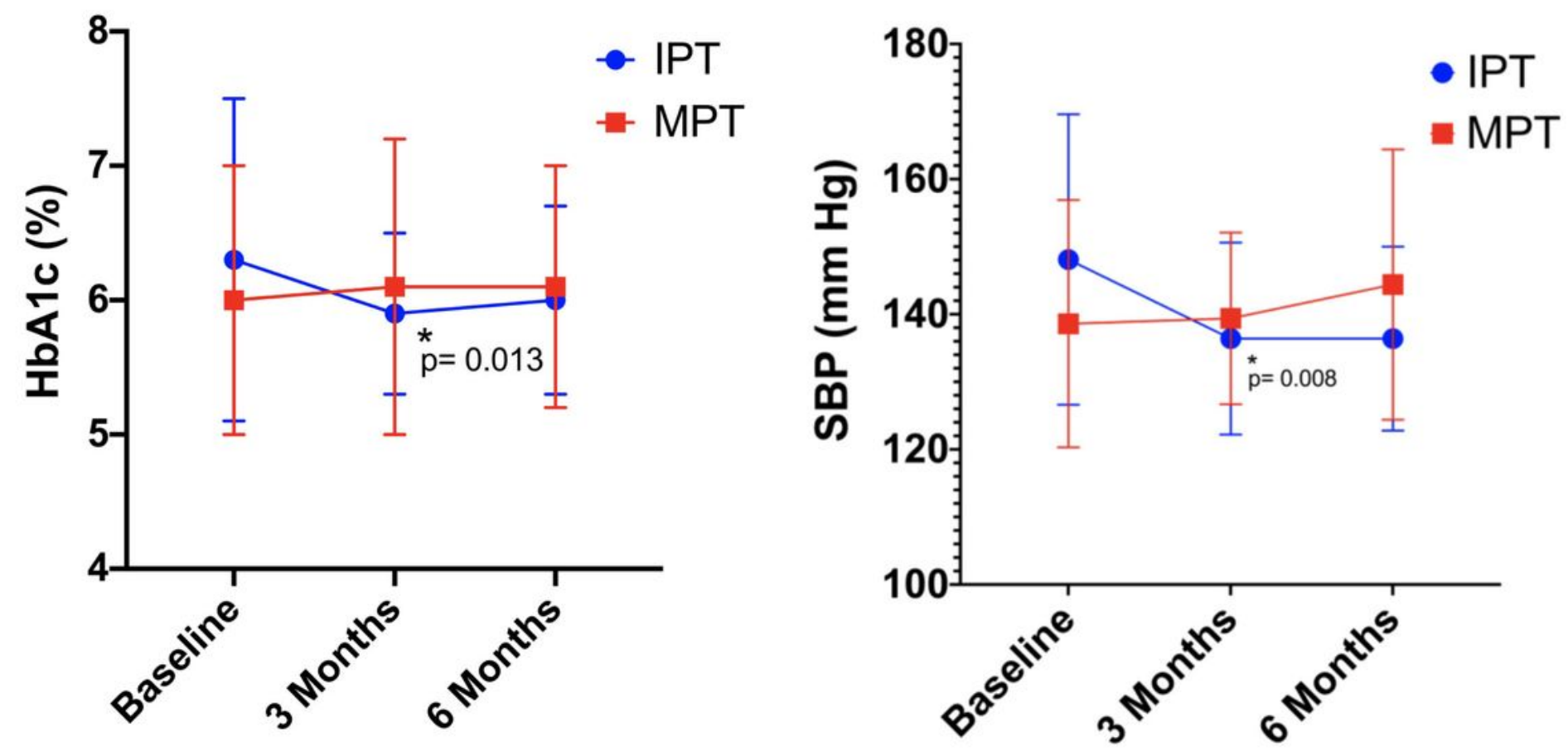

B)

D)
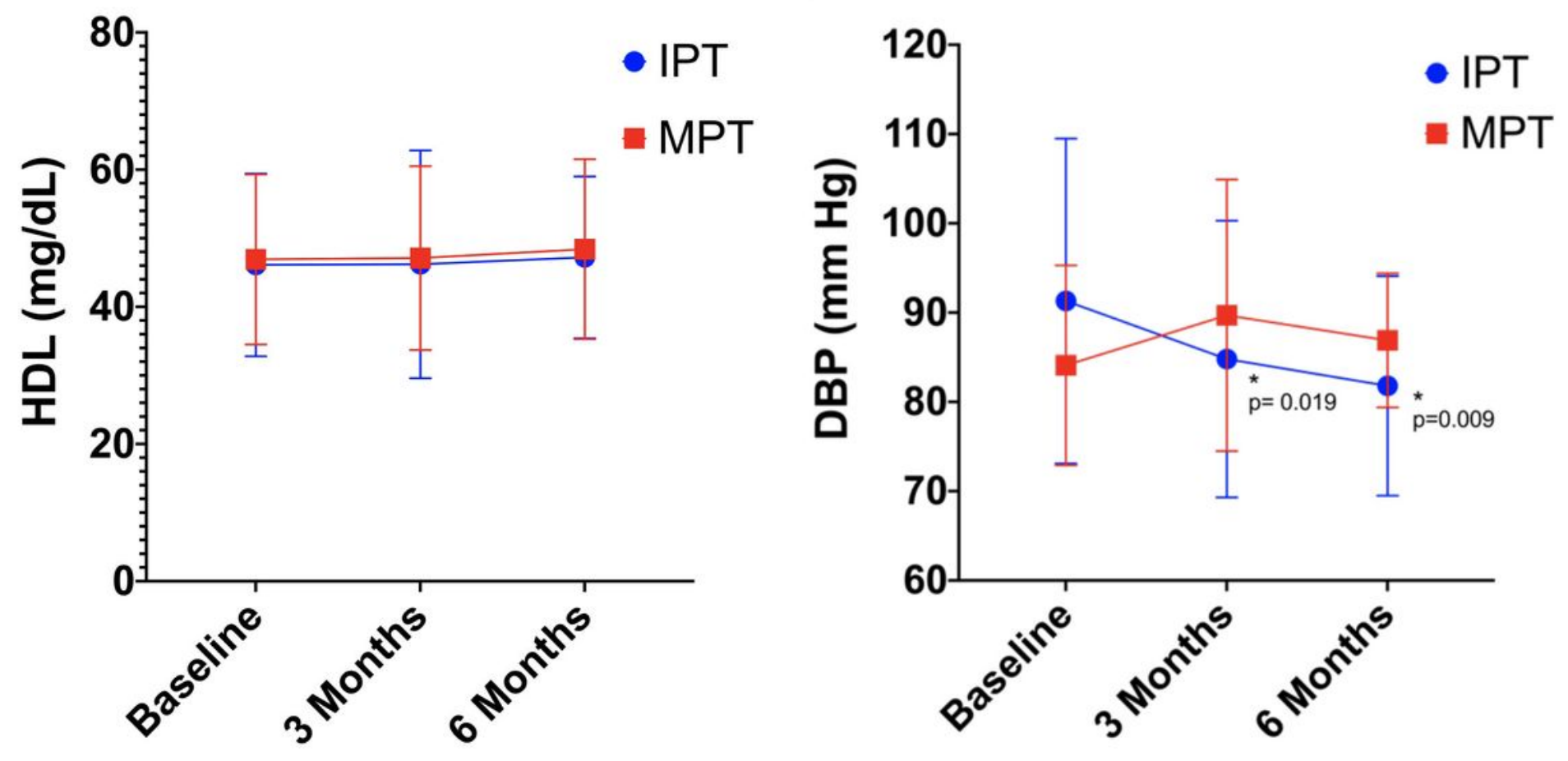

Figure 4

Metabolic and vascular measures at baseline and follow-up visits at 3 and 6 months. Data are unadjusted means and standard deviations (SDs); p-values are adjusted for age, sex, smoking, baseline values and body mass index. A) Glycated haemoglobin (HbA1c, \%) during the 6-month study period. B) High-density lipoproteins (HDL) during the 6-month study period. C) Systolic blood pressure (SBP) during the 6-month study period. D) Diastolic blood pressure (DBP) during the 6-month study period. 


\section{Supplementary Files}

This is a list of supplementary files associated with this preprint. Click to download.

- MetSRCTSupplementaryTables.docx

- MetSRCTSupplementaryTables.docx

- MetSCONSORTChecklist.doc

- MetSRCTSupplementaryMaterials.docx

- MetSRCTSupplementaryMaterials.docx

- MetSCONSORTChecklist.doc 